Canadian

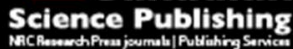

Canadian Geotechnical Journal Revue canadienne de géotechnique

\title{
Effects of Coupled Static and Dynamic Strain Rates on the Mechanical Behaviors of Rock-Like Specimens Containing Preexisting Fissures under Uniaxial Compression
}

\begin{tabular}{|r|l|}
\hline Journal: & Canadian Geotechnical Journal \\
\hline Manuscript ID & cgj-2017-0286.R2 \\
\hline Manuscript Type: & Article \\
\hline Complete List of Authors: & $\begin{array}{l}\text { Feng, Peng; Sichuan University, Key Laboratory of Geotechnical } \\
\text { Engineering of Sichuan Province } \\
\text { Dai, Feng; Sichuan University, Key Laboratory of Geotechnical Engineering } \\
\text { of Sichuan Province } \\
\text { Liu, Yi; Sichuan University, Key Laboratory of Geotechnical Engineering of } \\
\text { Sichuan Province } \\
\text { Xu, Nuwen; Sichuan University, Key Laboratory of Geotechnical } \\
\text { Engineering of Sichuan Province } \\
\text { Fan, Pengxian; PLA University of Science and Technology }\end{array}$ \\
\hline Keyword: & $\begin{array}{l}\text { Coupled loads, Strain rate, Mechanical behaviors, Energy characteristics, } \\
\text { Fissured specimen }\end{array}$ \\
\hline & \\
\hline
\end{tabular}




\title{
Effects of Coupled Static and Dynamic Strain Rates on the Mechanical Behaviors of Rock-Like Specimens Containing Preexisting Fissures under Uniaxial Compression
}

\author{
Peng Feng ${ }^{1}$, Feng Dai*, ${ }^{*}$, Yi Liu ${ }^{1}$, Nuwen Xu ${ }^{1}$, Pengxian Fan ${ }^{2}$ \\ ${ }^{1}$ State Key Laboratory of Hydraulics and Mountain River Engineering, College of \\ Water Resource and Hydropower, Sichuan University, Chengdu, Sichuan 610065, \\ China \\ ${ }^{2}$ State Key Laboratory of Disaster Prevention \& Mitigation of Explosion \& Impact, \\ Nanjing 210007, China \\ * Corresponding author Email: fengdai@scu.edu.cn (F. Dai)
}




\begin{abstract}
Rocks containing preexisting fissures in underground engineering are likely to be subjected to static pre-stress and dynamic loads simultaneously. Understanding the deformation and failure mechanism of fissured rocks under coupled static and dynamic strain rates is beneficial for the stability assessment of rock engineering structures. This study experimentally investigates the mechanical behaviors of fissured specimens under coupled static and dynamic loads with different loading parameters. Our experiments reveal that the coupled static-dynamic strain rates significantly affect the strength, deformation, energy characteristics and failure mode of fissured specimens. For each dynamic strain rate, the strength and elastic modulus of specimens feature an increase first as the static pre-stress increases up to half of the uniaxial compression strength, and then a decrease. However, for each static pre-stress of coupled loads, the strength and elastic modulus obviously increase with increasing dynamic strain rate. From the perspective of energy partition, for each static pre-stress, the higher dynamic strain rate induces the greater energy dissipation of the specimens during the coupled loading, and more elastic energy is released at the end of loading. Moreover, for each dynamic strain rate, the pre-stress of half uniaxial compression strength induces the highest released elastic energy.
\end{abstract}

Keywords: Coupled loads; Strain rate; Mechanical behaviors; Energy characteristics; Fissured specimen 


\section{Introduction}

Underground rock engineerings, such as oil exploitation, mining and geological boring, are likely to be subjected to static pre-stress and dynamic loads simultaneously (Fig. 1). Static pre-stress can be tectonic stress or gravity stress, and the dynamic loads may come from blasting, drilling or earthquakes (Chen et al. 2016a). In practice, rocks containing preexisting fissures widely exist in the underground projects, and are quite sensitive to coupled static-dynamic loading conditions. The existence of fissures significantly influences the strength and deformability of rocks in underground projects under different loading rates (Zhou et al. 2014). Therefore, understanding the effects of coupled static and dynamic strain rates on the mechanical behaviors of fissured rocks is significant for the stability evaluation in rock engineering applications.

In the laboratory, the servo-controlled testing machine (e.g., Instron, MTS) is generally utilized for applying the dynamic loading rates which corresponds to the strain rate of tested specimen ranging from $10^{-4} \mathrm{~s}^{-1}$ to $10^{-2} \mathrm{~s}^{-1}$. The split Hopkinson pressure bar (SHPB) system has been widely recognized to apply highly controlled dynamic loads (Dai et al. 2010; Dai et al. 2016; Zhang and Zhao 2014); the strain rate of the tested rock specimen generally surpasses $10^{1} \mathrm{~s}^{-1}$. So far, some scholars have investigated the mechanical behaviors of intact rocks under coupled static and dynamic loads, which differ from that under their corresponding individual static or dynamic loadings. Moreover, the failure modes of rock specimens can be significantly influenced by the dynamic loading of the coupled loads (Li et al. 2008; Yin et al. 2012). Zuo et al (2005) analyzed the damage and failure rule of intact rocks under coupled loads, and reported that the peak stress and elastic modulus decrease with increasing static pre-stress. However, in the dynamic loading stage of the coupled loads, all the rock specimens in these investigations are subjected to the stress wave loading, which is difficult to guarantee a constant strain rate of the tested specimen, especially during the post-peak failure stage in the stress-strain curve. 
Compared with the studies on intact rock specimens, existing studies on fissured specimens mainly concentrate on individual static or dynamic loadings. Under individual static loads, with the aid of high-speed photographic measurements (Lee and Jeon 2011), acoustic emission (AE) technology (Yang et al. 2017) and numerical methods (Zhang and Wong 2012; Zhao and Zhou 2016), the mechanical properties and crack coalescence behaviors of rock or rock-like specimens containing single, double or multiple pre-existing cracks have been systemically investigated ( $\mathrm{Li}$ and Wong 2012; Prudencio and Jan 2007; Wong and Einstein 2009). They concluded that the preexisting fissures significantly weaken the quasi-static strength and deformation properties of specimens; the failure modes are highly dependent on the geometrical configuration of fissures. In addition, using the SHPB system, some scholars studied the dynamic mechanical behaviors of specimens containing a single fissure with different inclination angles (Li et al. 2017; Zou and Wong 2014; Zou et al. 2016). Subjected to dynamic loads, the cracks often initiate from the periphery of preexisting fissures, forming an " $\mathrm{X}$ " shape on the surface of prismatic specimens.

However, to our best knowledge, the mechanical properties of fissured specimens under coupled static and dynamic loads have never been systematically studied. In this study, we conduct systematical experiments to investigate the mechanical properties of fissured specimens under different coupled static pre-stress and dynamic loads with strain rates ranging from $10^{-4} \mathrm{~s}^{-1}$ to $10^{-2} \mathrm{~s}^{-1}$. This range of strain rates is chosen in this study since it covers the main strain rates of structural materials including rock-like materials experienced by earthquake loading (Bischoff and Perry 1991; Li and Li 2012). By analyzing the fractal geometry and energy partition, the geometric morphology of crack surfaces and energy characteristics are also explored. This paper is organized as follows. The preparation of specimens and testing method are described in section 2. Section 3 introduces the calculation principle of the fractal dimension and energy density, followed by a comprehensive discussion about the testing results on the strength, elastic modulus, fractal dimension and energy density of fissured 
specimens under varying coupled static-dynamic loads in section 4. Section 5 summarizes the whole study.

\section{Experimental specimens and testing equipment}

\section{Specimen preparation}

Rock-like materials are utilized to prepare the testing specimens due to their convenience in fabricating fissures. The materials utilized in this study are made of a mixture of Portland cement, water, standard sand, silicon powder and water reducing agent at a mass ratio of 1: 0.35: 1.2: 0.15: 0.015. The standard sand and Portland cement are the main components of rock-like materials. The standard sand in the specimen can be regarded as grain, which influences the frictional behavior of the modeling material. The Portland cement works as the adhesive material between the grains (Cao et al. 2016). The average values of the uniaxial compressive strength, tensile strength and the elastic modulus of the modeling material are $64.8 \mathrm{MPa}, 6.1$ $\mathrm{MPa}$ and $10.34 \mathrm{GPa}$, respectively. To ensure homogeneity of the compound, the cement, standard sand, silicon powder and water reducing agent are thoroughly mixed. Subsequently, the mixed materials are casted in the customized molds (Fig. 2a). The intermittent fissures are prepared by first inserting the metal sheets $(0.4 \mathrm{~mm}$ thickness, $15 \mathrm{~mm}$ length) into the fresh rock-like materials at the specified locations and then removing them after $10 \mathrm{~h}$ of curing period. After 24 hours, the samples are kept in a special curing room (at temperature $20^{\circ} \mathrm{C}, 95 \%$ relative humidity) for 28 days. The

finally prepared fissured specimens are shown in Fig. 2b. Referring to the studies by Li et al (2001) and Liu et al (2017), the specimen dimensions (height $\times$ width $\times$ thickness) are selected as $200 \times 100 \times 100 \mathrm{~mm}$. Figure 3 show the geometrical definition of fissured specimen by four geometrical parameters. The fissure length $a=$ $15 \mathrm{~mm}$, the rock bridge length $b=15 \mathrm{~mm}$, fissure inclination angle $\beta=45^{\circ}$ and the spacing $d=18 \mathrm{~mm}$. 


\section{Test Schemes and Procedure}

Figure 4 shows the testing system, the tested fissured model and the loading path of fissured specimens. The MTS-793 testing system was employed in this study for all our tests (Fig. 4a). This equipment contains a compression loading frame, an axial loading system, and a data acquisition system, and is able to perform the uniaxial compression tests on rock-like specimens. The loading system has a $2750 \mathrm{KN}$ and a $2500 \mathrm{KN}$ load capacity for static and dynamic compression, respectively. The coupled static-dynamic loads are applied in two stages. First, in an axial displacement control mode at $0.005 \mathrm{~mm} / \mathrm{s}$ (strain rate is equal to $2.5 \times 10^{-5} \mathrm{~s}^{-1}$ ), the specimens are loaded up to the desired axial pre-stress varying from $20 \% \sigma_{\mathrm{c}}, 50 \% \sigma_{\mathrm{c}}$ to $80 \% \sigma_{\mathrm{c}}$, where $\sigma_{\mathrm{c}}$ denotes the static uniaxial compression strength of the specimen. In the second loading stage, dynamic loads are applied by transforming the loading velocity to 0.02 $\sim 2 \mathrm{~mm} / \mathrm{s}$ (the corresponding strain rate varies from $10^{-4} \mathrm{~s}^{-1}$ to $10^{-2} \mathrm{~s}^{-1}$ ). Tests on fissured specimens are conducted with different coupled loading conditions, and the details are tabulated in Table 1. For each specimen, an ID number is assigned using the notation $S-D$, where $S$ stands for the static pre-stress, and $D$ represents the strain rate of the specimen during the dynamic loading stage. For instance, $0.5-10^{-4}$ indicates that the applied static pre-stress equals to $0.5 \sigma_{\mathrm{c}}$ and the dynamic strain rate is $10^{-4} \mathrm{~s}^{-1}$. To minimize the boundary friction, two Teflon films coated with petrolatum are placed between the specimen and loading platforms. In addition, the crack propagation and coalescence on the sample surfaces are monitored by an industrial camera (JAI SP5000M-USB) at a frame rate of $134 \mathrm{fps}$. The resolution of the image obtained by this camera is $800 \times 1400$ pixels.

\section{The determination of fractal dimension and energy density}

\section{Fractal dimension}

The fractal theory has been employed in studying the physical and mechanical behaviors of rocks involving cracking network (Yang et al. 2016), porous structure (Ju et al. 2014), crack evolution process (Liu et al. 2016), etc. Since the fractal dimension 
quantitatively describe the irregular morphology of cracks (EI Ouahed et al. 2005; Laubach et al. 2000), the fractal theory is thus employed in this study to investigate the distribution and geometric morphology of cracks on the specimen surface. The box-counting dimension method (Zhang et al. 2015) is employed to calculate the fractal dimension of cracks. First, a binary image containing black (cracks) and white pixels (Fig.5) can be obtained by image processing on the specimen photos. Second, the binary image is divided into small squares with a certain size. Last, myriads of small squares with same geometry are utilized to cover all the cracks, and a series of $N_{\varepsilon}$ (the number of squares covering crack) can be acquired by changing the corresponding length $\varepsilon$ (Fig. 5c) of squares. The fractal dimension can be defined as follows:

$$
D=-\frac{\lg N_{\varepsilon}}{\lg (\varepsilon)}=\frac{\lg N_{\varepsilon}}{\lg (1 / \varepsilon)}
$$

In practice, a series of $1 / \varepsilon$ and $N \varepsilon$ are selected to calculate the slope of the straight line with double logarithmic coordinates, the slope can be regarded as the fractal dimension $D$.

\section{The determination of energy density}

During the testing, the deformation and failure of a specimen can be regarded as the process of energy dissipation and energy release (Chen et al. 2016b). Based on energy principles, the work done by external loads can be transfered into two categories of energy in an isothermal condition (Peng et al. 2015). One is the irreversible energy dissipated via the irreversible material deterioration and deformation. The other is the released elastic energy stored in material elements corresponding to the reversible elastic deformation. The dissipated and released elastic energies play pivotal roles in structural deformation and collapse. Considering the continuous evolution of inner micro-defects in specimens, the dissipated energy causes micro damage and irreversible deformation of the specimen, accompanied by strength deterioration. The sharp decrease of released elastic energy induces the catastrophic breakdown of the specimen. 
The damage of specimen continually occurs during the whole loading process (Meng et al. 2016). Initially, the accumulated input energy in the specimen slowly increases, and the original microcracks close and induce little energy dissipation. With further loading, the specimens constantly absorb energy and the stored energy is partially dissipated for the extension and coalescence of internal microcracks. The released elastic energy of the specimens is maximized at the peak strength, after that a substantial amount of stored elastic energy releases abruptly leading to the structural failure of specimens. Failure occurs as the elastic energy reaches the limitation of energy storage. In the perspective of energy, specimen strength represents the ability of energy store, and the higher specimen strength corresponds to the greater energy release.

Figure 6 shows a typical stress-strain curve of the fissured specimen, and the relationships between the dissipated energy and released elastic energy of the sample are illustrated. To quantify the dissipated energy and released elastic energy, two assumptions are proposed. First, the deformation and collapse process of the specimen is an isothermal process. Second, the rigidity of the testing machine is much higher than that of the specimen. The energy parameters are defined as follows. The total input energy density $U_{0}=U_{\mathrm{d}}+U_{\mathrm{e}}=\int_{0}^{\varepsilon_{2}} \sigma d \varepsilon$, is equal to the stored energy of a unit material volume, where $\sigma$ is the axial stress of specimen during the coupled loading and $\varepsilon_{2}$ is the axial strain corresponding to the peak coupled stress. The released elastic energy density $U_{\mathrm{e}}=\sigma_{\mathrm{sd}}{ }^{2} / 2 E$, where $E$ is the elastic modulus of the fissured specimen under coupled loads and $\sigma_{\mathrm{sd}}$ is the peak stress. The dissipated energy density $U_{\mathrm{d}}=$ $U_{0}-U_{\mathrm{e}}$. To further investigate the relationship between $U_{\mathrm{e}}$ and $U_{\mathrm{d}}$, the dissipated energy ratio $\beta_{\mathrm{d}}$ and released elastic energy ratio $\beta_{\mathrm{e}}$ are proposed using the following formulas: $\beta_{\mathrm{d}}=U_{\mathrm{d}} /\left(U_{\mathrm{d}}+U_{\mathrm{e}}\right) \times 100 \%$ and $\beta_{\mathrm{e}}=U_{\mathrm{e}} /\left(U_{\mathrm{d}}+U_{\mathrm{e}}\right) \times 100 \%$. 


\section{Results and discussion}

\section{Results of quasi-static uniaxial loading tests}

Before the coupled loading tests, conventional quasi-static compression tests were performed to obtain static mechanical parameters of the fissured specimen, which provides a reference for further studies. The stress-strain curves of three experimental fissured specimens under uniaxial compression are presented in Fig.7, featuring a slowly increasing part up to the peak stress and then an abrupt decreasing post-peak part. The detailed results are listed in Table 2 . The average static uniaxial compressive strength $\left(\sigma_{\mathrm{c}}\right)$ is $33.3 \mathrm{MPa}$ and the average elastic modulus is $7.6 \mathrm{GPa}$. Figure 8 shows the failure modes of the three specimens under quasi-static loading with experimental photos and binary images, in which the splitting tensile failure is domination in all specimens. In addition, the specimens show a similar failure scenario during loading process. Take the specimen U3 as an example (Fig. 9). The failure process of fissured specimens under quasi-static loading can be expressed with six typical stages, i.e., initial stage, $40 \%$ peak stress, $60 \%$ peak stress, $80 \%$ peak stress, $100 \%$ peak stress, and post $60 \%$ peak stress. From stage I (initial stage) to stage II (40\% peak stress), no obvious new cracks occur on the sample surface until the stress reaches the $40 \%$ peak stress. At stage II, cracks initiate from the tip of preexisting fissures and several wing-cracks can be observed. Through stage III (60\%) to stage IV (80\% peak stress), the cracks grow further, and an obvious network of tensile cracks appears on the specimen surface. In addition, the spalling can be observed at the loading stage IV. At stage V (100\% peak stress), these cracks further coalesce between preexisting fissures, resulting in a complicated cracking network. At stage VI (post 60\% peak stress), cracks completely link between preexisting fissures, featuring a tensile failure mode through the entire specimen.

\section{Strength and deformation of fissured specimens under different coupled loads}

Figures $10 \mathrm{a} \sim \mathrm{d}$ show the stress-strain curves of the tested specimens under coupled static-dynamic loads with static pre-stress of $0,0.2 \sigma_{\mathrm{c}}, 0.5 \sigma_{\mathrm{c}}$ and $0.8 \sigma_{\mathrm{c}}$, respectively. 
It can be observed that, the slopes of stress-strain curves obviously increase as the load changes from the quasi-static load to the dynamic load. In addition, for each static pre-stress, the slopes of stress-strain curves increase with increasing dynamic strain rate. Figure 11 shows the strengths of the fissured specimens under various coupled static and dynamic loads; the details are tabulated in Table 3. The strength of these specimens under various coupled static-dynamic loads varies from 33.9 to 45.9 MPa.

The relationship between the coupled strength and the dynamic strain rate of tested specimens under different coupled loads is shown in Fig. 12a. For each static pre-stress of the coupled loads, the strength obviously increases as the dynamic strain rate increases from $10^{-4} \mathrm{~s}^{-1}$ to $10^{-2} \mathrm{~s}^{-1}$. For each dynamic strain rate of the coupled loads, the tested specimens with different static pre-stress also exhibit different mechanical behaviors (Fig. 12b). The strength increases with increasing static pre-stress that is lower than $0.5 \sigma_{\mathrm{c}}$, and then decreases when the pre-stress further increases. This result might be explained as follows. When the stress of fissured specimen reaches the desired static pre-stress of $0.2 \sigma_{\mathrm{c}}$ (the tested specimen deforms in the elastic phase), the micro-cracks of specimen are compressed and closed which induce the decrease of micropore structures. When subjected to dynamic loads, the mechanical properties of the tested specimens can be enhanced and the strength of specimen with static pre-stress $0.2 \sigma_{\mathrm{c}}$ is thus higher than that of tests with no static pre-stress. When the stress of fissured specimen reaches desired static pre-stress of 0.5 $\sigma_{\mathrm{c}}$, the micro-cracks of specimen are compressed further and more micropore structures decrease compared with the specimen with a static pre-stress of $0.2 \sigma_{\mathrm{c}}$. Therefore, the strength of specimen with static pre-stress $0.5 \sigma_{\mathrm{c}}$ is even greater. However, when the static pre-stress reaches $0.8 \sigma_{\mathrm{c}}$, the cracks of specimens have already initiated and developed somehow in the specimen. In this case, the strength of specimen can be weakened before suffering the exterior dynamic load. Therefore, for each dynamic strain rate of coupled loads, the strength of fissured specimens under static pre-stress $0.8 \sigma_{\mathrm{c}}$ is lower than that of the static pre-stress $0.5 \sigma_{\mathrm{c}}$. 
As tabulated in Table 3, all the measured strengths under coupled loads are greater than that under quasi-static loading conditions. The related deviation ${ }^{\mathrm{a}}$ with respect to the strength of fissured specimen under quasi-static load varies from $1.8 \%$ to $37.8 \%$. Except for the specimen $0.8-10^{-4}$, the strength of fissured specimens under coupled loads is greater than that under individual dynamic loading. The relative deviation ${ }^{\mathrm{b}}$ with respect to the strength of specimen under individual dynamic load varies from $2.2 \%$ to $11.1 \%$. For each pre-stress of coupled loads, both the deviation ${ }^{\mathrm{a}}$ and deviation $^{b}$ increase with increasing dynamic strain rate, which indicates that the strength variation of the specimens is more sensitive under higher dynamic strain rates. However, for any dynamic strain rate of coupled loads, the deviation ${ }^{\mathrm{a}}$ and deviation $^{\mathrm{b}}$ increase when the static pre-stress increases from 0 to $0.5 \sigma_{\mathrm{c}}$, and then decrease when the static pre-stress surpasses $0.5 \sigma_{\mathrm{c}}$. The mechanical behaviors of specimens under coupled static-dynamic loads give a reference on engineering constructions. Under dynamic loading conditions, the strength of engineering rocks containing preexisting fissures might be quite high when the static pre-stress acting on them is around $0.5 \sigma_{\mathrm{c}}$.

The elastic moduli of fissured specimens are calculated under different coupled loading conditions. As shown in Fig. 13a, the coupled static-dynamic loads evidently affect the elastic modulus of the fissured specimens. Figure $13 \mathrm{~b}$ reveals the influence of the static pre-stress on the elastic modulus of fissured specimens. The strain rate effect on the elastic modulus of fissured specimens is prominent. For each static pre-stress of coupled loads, the elastic modulus of fissured specimens obviously increases as the dynamic strain rate increases from $10^{-4} \mathrm{~s}^{-1}$ to $10^{-2} \mathrm{~s}^{-1}$. However, For each dynamic strain rate of the coupled loads, the elastic modulus of fissured specimen increases with the pre-stress increases from 0 to $0.5 \sigma_{\mathrm{c}}$, and then decreases when the static pre-stress exceeds $0.5 \sigma_{\mathrm{c}}$ (Fig. 13c).

Table 4 lists all the determined elastic modulus of fissured specimens under coupled static-dynamic loads, which varies from 7.5 to $10.3 \mathrm{GPa}$. Except for the specimen $0.8-10^{-4}$, all the elastic modulus of fissured specimens under coupled loads is greater than that under the individual static loading. The deviation ${ }^{\mathrm{c}}$ with respect to 
the elastic modulus of fissured specimen under quasi-static load varies from $4.0 \%$ to $35.5 \%$, and the deviation ${ }^{c}$ increases with increasing dynamic strain rate. When the pre-stress of the specimen ranges from 0 to $0.5 \sigma_{\mathrm{c}}$, the elastic modulus of fissured specimens under coupled loads is greater than that under the individual dynamic loading. The relative deviation ${ }^{\mathrm{d}}$ with respect to the elastic modulus of specimens under the individual dynamic loading varies from $1.1 \%$ to $12.0 \%$, and the deviation ${ }^{\mathrm{d}}$ increases with increasing static pre-stress. Nevertheless, for the static pre-stress of $0.8 \sigma_{\mathrm{c}}$, the elastic modulus of fissured specimens is lower than that under the individual dynamic loading condition.

\section{Coalescence categories and failure modes}

The crack coalescence and failure modes of fissured specimens under different coupled static-dynamic loads are observed by virtue of the industrial camera. In general, when the fissured specimen is subjected to coupled static-dynamic loads, cracks initiate from the tip of fissures due to local stress concentration. With further loading, new cracks propagate and coalesce until adjacent fissures link with each other. Eventually, due to the coalescence of multiple fissures, the specimens fail in various modes. Experimental observations reveal that the tensile crack plays a significant role in the coalescence of preexisting fissures. The coalescence patterns between adjacent fissures can be classified into four categories (Figs. 14a $\sim$ d). The coalescence category I (Fig. 14a) occurs through wing cracking from inner tip of a fissure to the inner tip of another fissure. The coalescence category II (Fig. 14b) is produced by the linkage of anti-wing cracks between inner tips of two fissures. In coalescence category III (Fig. 14c), fissure tips at the same side of the two preexisting fissures (outer tip of fissure 1 to inner tip of fissure 2 or inner tip of fissure 1 to outer tip of fissure 2) are linked up by a tensile crack. In coalescence category IV (Fig. 14d), the tensile wing crack or anti-wing crack initiates from the tip of one fissure and then propagate towards the surface of another fissure. The corresponding coalescence categories in typical fissured specimens are shown in Fig. 14e. 
Figures $15 \sim 18$ show the experimental and binary images on the failure modes of the fissured specimen under different coupled static-dynamic loads. Each specimen is described by two loading stages i.e., the loading stage with the prescript static pre-stress and the peak stress stage. As the pre-stress is zero (Fig. 15), it can be observed that the cracks coalesce completely between preexisting fissures at the peak stress stage. The specimens with different dynamic strain rates show a similar tensile cracking network and all the coalescence categories can be found in these specimens with different strain rates. In special, the specimens with the dynamic strain rates of $10^{-4} \mathrm{~s}^{-1}$ and $10^{-3} \mathrm{~s}^{-1}$, the coalescence between two preexisting fissures depicts the cracking pattern containing two or three classified categories. When the prescript pre-stress is $20 \% \sigma_{\mathrm{c}}$ (Fig. 16), no cracks are visible on the specimen surface. At the critical loading stage at the peak stress, the coalescence category I, II and III can be easily observed in the specimens with the dynamic strain rates of $10^{-4} \mathrm{~s}^{-1}$ and $10^{-3} \mathrm{~s}^{-1}$. However, for the specimens with the dynamic strain rate of $10^{-2} \mathrm{~s}^{-1}$, the coalescence between two preexisting fissures generally contains multiple classified categories. Figure 17 shows that, given a prescript pre-stress of $50 \% \sigma_{\mathrm{c}}$, noticeable tensile cracks initiate from fissure tips and coalesce to some extent. With further dynamic loading up to the peak stress, the preexisting fissures of specimens are linked by tensile wing-cracks and anti-wing cracks. In addition, the coalescence category IV is hardly observed in these specimens. For the pre-stress reaches the $80 \% \sigma_{\mathrm{c}}$ (Fig. 18), specimens have been remarkably cracked, with myriads of tensile cracks initiating and propagating to the loading direction. At the critical loading stage (i.e., peak stress), these cracks further coalesce among preexisting fissures, resulting in a complex cracking network interacting with wing cracks and anti-wing cracks. In general, the mixed coalescence pattern, including more than one classified category, is more likely to be encountered in these specimens.

\section{The fractal characteristics of crack surfaces}

Based on the fractal principles, a computer program is developed to calculate the fractal dimension of cracks of specimens at the critical loading stage with peak stress 
(Figs. 15 18). The fractal dimension of cracks under different coupled loads varies from 1.741 to 1.792 with a deviation around $2.9 \%$. The effects of dynamic loading rates on the fractal dimension of specimens are shown in Fig. 19a. For each static pre-stress of coupled loads, the fractal dimension obviously increases as the dynamic strain rate increases from $10^{-4} \mathrm{~s}^{-1}$ to $10^{-2} \mathrm{~s}^{-1}$. Similarly, for each dynamic strain rate of coupled loads, the fractal dimension of the crack surfaces increases with the increase of static pre-stress (Fig. 19b).

For traditional Euclidean geometrical space, the dimensions of point, line, plane and body are zero to three, respectively. Fractal dimension breaks through the traditional viewpoint of Euclidean dimensions. The value of fractal dimension of a plane is generally between 1 and 2. A larger fractal dimension is associated with a more complex curve and results in a larger amount of the filled plane. In our study, the value of fractal dimension reflects the distribution and morphology of cracks on sample surfaces. A higher dynamic strain or a higher static pre-stress of coupled loads induce a higher fractal dimension corresponding to more complex cracking network in the specimen surfaces. In contrast, for the fissured specimens subjected to lower dynamic strain or lower static pre-stress, fewer macroscopic cracks appear.

\section{Energy characteristics of specimens under coupled loads}

Table 5 lists all the calculated dissipated energy density and released elastic energy density of fissured specimens. When compared with the dissipated energy, more released elastic energy stores in the fissured specimen at the critical loading stage (i.e., peak stress). The total input energy density of the fissured specimens under coupled static-dynamic loads varies from 86.6 to $139.6 \mathrm{~kJ} / \mathrm{mm}^{3}$. For each static pre-stress, as the dynamic strain rate increases from $10^{-4} \mathrm{~s}^{-1}$ to $10^{-2} \mathrm{~s}^{-1}$, the total input energy density increases. However, for each dynamic strain rate, the total input energy density of the fissured specimen increases with the increased static pre-stress that is less than $0.5 \sigma_{\mathrm{c}}$, and then decreases. 
Figure 20a depicts the influence of the dynamic loads on the dissipated energy density of specimens under coupled loading. For each static pre-stress of coupled loads, as the dynamic strain rate increases from $10^{-4} \mathrm{~s}^{-1}$ to $10^{-2} \mathrm{~s}^{-1}$, the dissipated energy density obviously increase with the increase of dynamic strain rate. In other words, the higher dynamic strain rate of coupled loads induces more energy dissipation during coupled loading conditions. This result agrees with the effect of the dynamic strain rate on fractal dimension of crack surfaces (Fig. 19a). It can thus be concluded that the higher dynamic loading induces the more dissipated energy and forms more complex cracking networks in specimens during coupled loading process.

The relationship between the released elastic energy and the dynamic strain rate of fissured specimens is shown in Fig. 20b. For each static pre-stress of coupled loads, the released elastic energy density evidently increases with increasing dynamic strain rate. In other words, under higher dynamic loading, more energy of fissured specimen can be released at the end of loading. Moreover, the dissipated energy density ratio of the fissured specimen, which varies from $14.1 \%$ to $26.0 \%$, decreases with the increase of dynamic strain rate. In contrast, the released elastic energy density ratio of the fissured specimen, varying from $74.0 \%$ to $85.9 \%$, increases with the increase of dynamic strain rate.

Figure 20c shows the dissipated energy density of fissured specimens versus static pre-stress. For each dynamic strain rate of coupled loads, with increasing static pre-stress, the dissipated energy density of the fissured specimen increases obviously. This result matches the effect of static pre-stress on fractal dimension of crack surfaces (Fig. 19b). Through analyzing the results of fractal dimension and dissipated energy density of specimens with different static pre-stress, we can conclude that, during coupled loading process, the fissured specimen under higher static pre-stress dissipates more energy and forms more irregular cracking profiles.

The effects of static pre-stress on released elastic energy of specimens are shown in Fig. 20d. For each dynamic strain rate, the released elastic energy density of the fissured specimen under the static pre-stress $\left(0.5 \sigma_{\mathrm{c}}\right)$ is the highest, and those with 
relative low $\left(0.2 \sigma_{\mathrm{c}}\right)$ and high $\left(0.8 \sigma_{\mathrm{c}}\right)$ static pre-stress are also higher than those without static pre-stress. This scenario reveals that, for engineering rock mass with the static pre-stress around $0.5 \sigma_{\mathrm{c}}$, when subjected to the exterior dynamic loading, the most elastic energy can be released in a short time and the failure of rocks can be drastic.

\section{Conclusions}

In this study, the mechanical behaviors of fissured specimens under coupled static and dynamic loads are systemically investigated. With the aid of the fractal geometry and energy partition analysis, the geometric morphology of crack surfaces and energy characteristics are also explored. The dynamic load superposed on a static pre-stress has the analogical influence on the strength and elastic modulus of fissured specimens. Except for the specimens with a static pre-stress of $0.8 \sigma_{\mathrm{c}}$, the strength and elastic modulus of fissured specimens under coupled loads is higher than that under individual static or dynamic loading conditions. For each static pre-stress of coupled loads, the mechanical properties of fissured specimens, including the coupled strength and elastic modulus, are highly dependent on strain rate. In addition, for each dynamic strain rate of coupled loads, the strength and elastic modulus of specimens increase as the static pre-stress increases from 0 to $0.5 \sigma_{\mathrm{c}}$, and then decreases as the static pre-stress surpasses $0.5 \sigma_{\mathrm{c}}$.

In view of cracking morphology, the higher dynamic strain rate and higher static pre-stress on specimens induce the greater fractal dimension of cracks, which corresponds to more irregular cracking network in the specimen. The coupled static-dynamic loads also affect the energy features of specimens. For each static pre-stress of coupled loads, the higher dynamic strain rate induces the greater dissipated energy density and released elastic energy density of the fissured specimens. In other words, for the fissured specimens with higher dynamic strain rate during coupled loadings, more energy dissipates and more elastic energy can be released. For each dynamic strain rate of coupled loads, the released elastic energy density 
increases with increasing static pre-stress that is less than $0.5 \sigma_{\mathrm{c}}$, and then decreases. The dissipated energy density increases obviously with increasing static pre-stress. This result indicates that higher static pre-stress induces greater energy dissipation of the fissured specimen and forms the more complex cracking network during coupled static-dynamic loading.

\section{Acknowledgments}

The authors are grateful for the financial support from the National Program on Key Basic Research Project (No. 2015CB057903) and National Natural Science Foundation of China (No. 51679158).

\section{References}

Bischoff, P.H., and Perry, S.H. 1991. Compressive behaviour of concrete at high strain rates. Materials and structures, 1991, 24: 425-450.

Cao, R.H., Cao, P., Lin, H., Pu, C.Z., and Ou, K. 2016. Mechanical behavior of brittle rock-like specimens with pre-existing fissures under uniaxial loading: experimental studies and particle mechanics approach. Rock Mechanics and Rock Engineering, 49: 763-783.

Chen, R., Li, K., Xia, K.W., Lin, Y.L., Yao, W., and Lu, F.Y. 2016a. Dynamic fracture properties of rocks subjected to static pre-load using notched semi-circular bend method. Rock Mechanics and Rock Engineering, 49: 3866-3872.

Chen, W., Konietzky, H., Tan, X., and Frühwirt, T. 2016b. Pre-failure damage analysis for brittle rocks under triaxial compression. Computers and Geotechnics, 74: 45-55.

Dai, F., Huang, S., Xia, K., and Tan, Z. 2010. Some fundamental issues in dynamic compression and tension tests of rocks using split Hopkinson pressure bar. Rock Mechanics and Rock Engineering, 43: 657-666.

Dai, F., Xu, Y., Zhao, T., Xu, N.W., and Liu, Y. 2016. Loading-Rate-Dependent Progressive Fracturing of Cracked Chevron-Notched Brazilian Disk Specimens in Split Hopkinson Pressure Bar Tests, International Journal of Rock Mechanics and Mining Sciences, 88:49-60

EI Ouahed, A.K., Tiab, D., and Mazouzi, A. 2005. Application of artificial intelligence to characterize naturally fractured zones in Hassi Messaoud Oil Field. Journal of Petroleum Science and Engineering, 49: 122-141. 
Ju, Y., Zheng, J.T., Epstein, M., Sudak, L., Wang, J.B., and Zhao, X. 2014. 3D numerical reconstruction of well-connected porous structure of rock using fractal algorithms. Computer Methods in Applied Mechanics and Engineering, 279: $212-226$.

Laubach, S., Marrett, R., and Olson, J. 2000. New directions in fracture characterization. The Leading Edge, 19: 704-711.

Lee, H., and Jeon, S. 2011. An experimental and numerical study of fracture coalescence in pre-cracked specimens under uniaxial compression. International Journal of Solids and Structures, 48: 979-999.

Li, H., and Wong, L.N.Y. 2012. Influence of flaw inclination angle and loading condition on crack initiation and propagation. International Journal of Solids and Structures, 49: 2482-2499.

Li, M., and Li, H. 2012. Effects of strain rate on reinforced concrete structure under seismic loading. Advances in Structural Engineering, 15: 461-475.

Li, N., Chen, W., Zhang, P., and Swoboda, G. 2001. The mechanical properties and a fatigue-damage model for jointed rock masses subjected to dynamic cyclical loading. International Journal of Rock Mechanics and Mining Sciences, 38: 1071-1079.

Li, X.B., Zhou, Z.L., Lok, T.S., Hong, L., and Yin, T.B. 2008. Innovative testing technique of rock subjected to coupled static and dynamic loads. International Journal of Rock Mechanics and Mining Sciences, 45: 739-748.

Li, X.B., Zhou, T., and Li, D.Y. 2017. Dynamic strength and fracturing behavior of single-flawed prismatic marble specimens under impact loading with a split-hopkinson pressure bar. Rock Mechanics and Rock Engineering, 50: 29-44.

Liu, C., Xue, J.H., Yu, G.F., and Cheng, X.Y. 2016. Fractal characterization for the mining crack evolution process of overlying strata based on microseismic monitoring technology. International Journal of Mining Science and Technology, 26: 295-299.

Liu, Y., Dai, F., Fan, P.X., Xu, N.W., and Dong, L. 2017. Experimental investigation of the influence of joint geometric configurations on the mechanical properties of intermittent jointed rock models under cyclic uniaxial compression. Rock Mechanics and Rock Engineering, 50:1453-1471.

Meng, Q.B., Zhang, M.W, Han, L.J., Pu, H., and Nie, T.Y. 2016. Effects of acoustic emission and energy evolution of rock specimens under the uniaxial cyclic Loading and Unloading Compression, Rock Mechanics and Rock Engineering. 49: 3873-3886.

Peng, R.D., Ju, Y., Wang, J.G., Xie, H.P., Gao, F., and Mao, L.T. 2015. Energy dissipation and release during coal failure under conventional triaxial 
compression. Rock Mechanics and Rock Engineering, 48: 509-526.

Prudencio, M., and Jan, M.V. 2007. Strength and failure modes of rock mass models with non-persistent joints. International Journal of Rock Mechanics and Mining Sciences, 44: 890-902.

Wong, L.N.Y., and Einstein, H.H. 2009. Systematic evaluation of cracking behavior in specimens containing single flaws under uniaxial compression. International Journal of Rock Mechanics and Mining Sciences, 46: 239-249.

Yang, S.Q., Huang, Y.H., Tian, W.L., and Zhu, J.B. 2017. An experimental investigation on strength, deformation and crack evolution behavior of sandstone containing two oval flaws under uniaxial compression. Engineering Geology, 217: 35-48.

Yang, Y., Ju, Y., Li, F., Gao, F., and Sun, H. 2016. The fractal characteristics and energy mechanism of crack propagation in tight reservoir sandstone subjected to triaxial stresses. Journal of Natural Gas Science and Engineering, 32: 415-422.

Yin, Z.Q., Li, X.B., Jin, J.F., He, X.Q., and Du, K. 2012. Failure characteristics of high stress rock induced by impact disturbance under confining pressure unloading. Transactions of Nonferrous Metals Society of China, 22: 175-184.

Zhang, Q.B., and Zhao, J. 2014. A review of dynamic experimental techniques and mechanical behaviour of rock materials. Rock Mechanics and Rock Engineering, 47: 1411-1478.

Zhang, R., Dai, F., Gao, M.Z., Xu, N.W., and Zhang, C.P. 2015. Fractal analysis of acoustic emission during uniaxial and triaxial loading of rock. International Journal of Rock Mechanics and Mining Sciences, 79: 241-249.

Zhang, X.P., and Wong, L.N.Y. 2012. Cracking processes in rock-like material containing a single flaw under uniaxial compression: a numerical study based on parallel bonded-particle model approach. Rock Mechanics and Rock Engineering, 45: 711-737.

Zhao, Z.H., and Zhou, D. 2016. Mechanical properties and failure modes of rock samples with grout-infilled flaws: A particle mechanics modeling. Journal of Natural Gas Science and Engineering, 34: 702-715.

Zhou, X.P., Cheng, H., and Feng, Y.F. 2014. An experimental study of crack coalescence behaviour in rock-like materials containing multiple flaws under uniaxial compression. Rock Mechanics and Rock Engineering, 47: 19611986.

Zou, C., and Wong, L.N.Y. 2014. Experimental studies on cracking processes and failure in marble under dynamic loading. Engineering Geology, 173: 19-23

Zou, C., Wong, L.N.Y., Loo, J.J., and Gan, B.S. 2016. Different mechanical and 
cracking behaviors of single-flawed brittle gypsum specimens under dynamic and quasi-static loadings. Engineering Geology, 201: 71-84.

Zuo, Y.J., Li, X.B., Ma, C.D., Zhang Y.P., and Wang W.H. 2005. Damage and failure rule of rock undergoing uniaxial compressive load and dynamic load. Journal of Central South University of Technology, 12: 742-748. 


\section{Figure Captions}

Fig. 1 Schematic diagram of a rock structure at depth subjected to coupled static and dynamic loads

Fig. 2 (a) Customized mold of the rock-like specimen containing intermittent fissures and (b) the fissured specimens prepared for our tests

Fig. 3 Schematic of the geometric configurations of the fissured specimen

Fig. 4 (a) The MTS-793 rock test system and (b) the tested fissured model and the loading path of coupled static-dynamic loads $\left(\sigma_{\mathrm{s}}\right.$ represents the static pre-stress, $\sigma_{\mathrm{d}}$ is the dynamic loading stress, $\sigma_{\mathrm{sd}}$ is the strength at the coupled loading condition)

Fig. 5 The binary reference model (a) the experimental image, (b) the binary image, and (c) the calculated pixels

Fig. 6 Quantitative relationship of the energy release and the energy dissipation

Fig.7 The stress-strain curves of the three tested fissured samples under quasi-static uniaxial compression

Fig. 8 Failure modes of the three fissured samples under quasi-static uniaxial compression

Fig. 9 Progressive failure behavior of the fissured specimen U3 under quasi-static uniaxial compression

Fig. 10 Stress-strain curves of fissured specimens under coupled loads with static pre-stress of (a) 0 , (b) $0.2 \sigma_{\mathrm{c}}$, (c) $0.5 \sigma_{\mathrm{c}}$ and (d) $0.8 \sigma_{\mathrm{c}}$.

Fig. 11 Strengths of fissured specimens under various coupled static-dynamic loads

Fig. 12 Influences of (a) the static pre-stress and (b) the dynamic strain rate on the strength of fissured specimens under coupled loads

Fig. 13 (a) The determination of the elastic modulus of a fissured specimen under coupled static-dynamic loads, and influences of (b) the dynamic strain rate and (c) the static pre-stress on the elastic modulus of fissured specimens under coupled loads 
Fig. 14 Coalescence categories of fissured specimens under different coupled static-dynamic loads

Fig. 15 The failure modes of the fissured specimen with zero pre-stress under dynamic strain rates of (a) $10^{-4} \mathrm{~s}^{-1}$, (b) $10^{-3} \mathrm{~s}^{-1}$, and (c) $10^{-2} \mathrm{~s}^{-1}$

Fig. 16 The failure modes of the fissured specimen with a pre-stress of $0.2 \sigma_{\mathrm{c}}$ under dynamic strain rates of (a) $10^{-4} \mathrm{~s}^{-1}$, (b) $10^{-3} \mathrm{~s}^{-1}$, and (c) $10^{-2} \mathrm{~s}^{-1}$

Fig. 17 The failure modes of the fissured specimen with a pre-stress of $0.5 \sigma_{\mathrm{c}}$ under dynamic strain rates of (a) $10^{-4} \mathrm{~s}^{-1}$, (b) $10^{-3} \mathrm{~s}^{-1}$, and (c) $10^{-2} \mathrm{~s}^{-1}$

Fig. 18 The failure modes of the fissured specimen with a pre-stress of $0.8 \sigma_{\mathrm{c}}$ under dynamic strain rates of (a) $10^{-4} \mathrm{~s}^{-1}$, (b) $10^{-3} \mathrm{~s}^{-1}$, and (c) $10^{-2} \mathrm{~s}^{-1}$

Fig. 19 Influences of (a) the dynamic strain rate and (b) the static pre-stress on the fractal dimension of crack surfaces of fissured specimens under coupled loads

Fig. 20 Influences of the dynamic strain rate on (a) the dissipated energy density and (b) the released elastic energy density, and influences of the static pre-stress on (c) the dissipated energy density and (d) the released elastic energy density 


\section{Table 1}

Parameters of the coupled static-dynamic loads during the tests

\begin{tabular}{cccc}
\hline Static pre-stress & Dynamic strain rate $\left(\mathrm{s}^{-1}\right)$ & Static pre-stress & Dynamic strain rate $(\mathrm{mm} / \mathrm{s})$ \\
\hline $0 \sigma_{\mathrm{c}}$ & $10^{-4}$ & & $10^{-4}$ \\
& $10^{-3}$ & $0.2 \sigma_{\mathrm{c}}$ & $10^{-3}$ \\
$0.5 \sigma_{\mathrm{c}}$ & $10^{-2}$ & & $10^{-2}$ \\
& $10^{-4}$ & $0.8 \sigma_{\mathrm{c}}$ & $10^{-4}$ \\
\hline & $10^{-3}$ & & $10^{-2}$ \\
\hline
\end{tabular}

Note: $\sigma_{\mathrm{c}}$ is the quasi-static uniaxial compression strength of the specimen.

\section{Table 2}

Measured strengths and elastic moduli of fissured specimens in quasi-static uniaxial compression tests

\begin{tabular}{ccc}
\hline Specimen & Strength $(\mathrm{MPa})$ & Elastic modulus $(\mathrm{GPa})$ \\
\hline U1 & 34.3 & 7.7 \\
U2 & 33.2 & 7.5 \\
U3 & 32.5 & 7.6 \\
Average & 33.3 & 7.6 \\
\hline
\end{tabular}




\section{Table 3}

Strengths of the fissured specimens under coupled static-dynamic loads

\begin{tabular}{lccc}
\hline \multicolumn{1}{c}{ Notation } & Strength (MPa) & Deviation $^{\mathrm{a}}(\%)$ & Deviation $^{\mathrm{b}}(\%)$ \\
\hline $0-2.5 \times 10^{-5}$ & 33.3 & & \\
$0-10^{-4}$ & 34.5 & 3.6 & \\
$0-10^{-3}$ & 36.8 & 10.5 & \\
$0-10^{-2}$ & 41.3 & 24.0 & \\
$0.2-10^{-4}$ & 36.3 & 9.0 & 5.2 \\
$0.2-10^{-3}$ & 38.9 & 16.8 & 5.7 \\
$0.2-10^{-2}$ & 44.3 & 33.0 & 7.3 \\
$0.5-10^{-4}$ & 36.9 & 10.8 & 7.0 \\
$0.5-10^{-3}$ & 40.4 & 21.3 & 9.8 \\
$0.5-10^{-2}$ & 45.9 & 37.8 & 11.1 \\
$0.8-10^{-4}$ & 33.9 & 1.8 & -1.7 \\
$0.8-10^{-3}$ & 37.6 & 12.9 & 2.2 \\
$0.8-10^{-2}$ & 42.8 & 18.5 & 3.6 \\
\hline
\end{tabular}

Note: ${ }^{a}$ Deviation with respect to the strength of fissured specimen under individual quasi-static load

${ }^{b}$ Deviation with respect to the strength of fissured specimen under individual dynamic load

\section{Table 4}

Elastic moduli of the fissured specimens under coupled static-dynamic loads

\begin{tabular}{lccc}
\hline \multicolumn{1}{c}{ Notation } & Elastic modulus (GPa) & Deviation $^{\mathrm{c}}(\%)$ & Deviation $^{\mathrm{d}}(\%)$ \\
\hline $0-2.5 \times 10^{-5}$ & 7.6 & & \\
$0-10^{-4}$ & 7.9 & 4.0 & \\
$0-10^{-3}$ & 8.6 & 13.2 & \\
$0-10^{-2}$ & 9.2 & 21.1 & \\
$0.2-10^{-4}$ & 8.1 & 6.6 & 2.5 \\
$0.2-10^{-3}$ & 8.7 & 14.5 & 1.2 \\
$0.2-10^{-2}$ & 9.3 & 22.4 & 1.1 \\
$0.5-10^{-4}$ & 8.5 & 11.8 & 7.6 \\
$0.5-10^{-3}$ & 9.4 & 23.7 & 9.3 \\
$0.5-10^{-2}$ & 10.3 & 35.5 & 12.0 \\
$0.8-10^{-4}$ & 7.5 & -1.3 & -5.1 \\
$0.8-10^{-3}$ & 8.0 & 5.3 & -7.0 \\
$0.8-10^{-2}$ & 8.8 & 15.8 & -4.4 \\
\hline
\end{tabular}

Note: ${ }^{\mathrm{c}}$ Deviation with respect to the elastic modulus of fissured specimen under individual quasi-static load

${ }^{d}$ Deviation with respect to the elastic modulus of fissured specimen under individual dynamic load 


\section{Table 5}

Calculated results of dissipated energy density and released elastic energy density $\left(\mathrm{kJ} / \mathrm{mm}^{3}\right)$ of fissured specimens under coupled static-dynamic loads

\begin{tabular}{lccccc}
\hline \multicolumn{1}{c}{ Notation } & $U_{\mathrm{d}}$ & $U_{\mathrm{e}}$ & $\beta_{\mathrm{d}}(\%)$ & $\beta_{\mathrm{e}}(\%)$ & Total energy \\
\hline $0-2.5 \times 10^{-5}$ & 12.6 & 63.5 & 16.6 & 83.4 & 76.1 \\
$0-10^{-4}$ & 13.7 & 72.9 & 15.8 & 84.2 & 86.6 \\
$0-10^{-3}$ & 14.5 & 81.8 & 15.1 & 84.9 & 96.3 \\
$0-10^{-2}$ & 15.1 & 92.3 & 14.1 & 85.9 & 107.4 \\
$0.2-10^{-4}$ & 16.7 & 78.1 & 17.6 & 82.4 & 94.8 \\
$0.2-10^{-3}$ & 17.0 & 88.6 & 16.1 & 83.9 & 105.6 \\
$0.2-10^{-2}$ & 17.3 & 99.9 & 14.8 & 85.2 & 117.2 \\
$0.5-10^{-4}$ & 25.9 & 90.4 & 22.3 & 77.7 & 116.3 \\
$0.5-10^{-3}$ & 27.2 & 95.8 & 22.1 & 77.9 & 123.0 \\
$0.5-10^{-2}$ & 30.3 & 107.7 & 22.0 & 78.0 & 138.0 \\
$0.8-10^{-4}$ & 28.7 & 85.1 & 25.2 & 74.8 & 113.8 \\
$0.8-10^{-3}$ & 32.1 & 91.5 & 26.0 & 74.0 & 123.6 \\
$0.8-10^{-2}$ & 35.1 & 104.5 & 25.1 & 74.9 & 139.6 \\
\hline
\end{tabular}




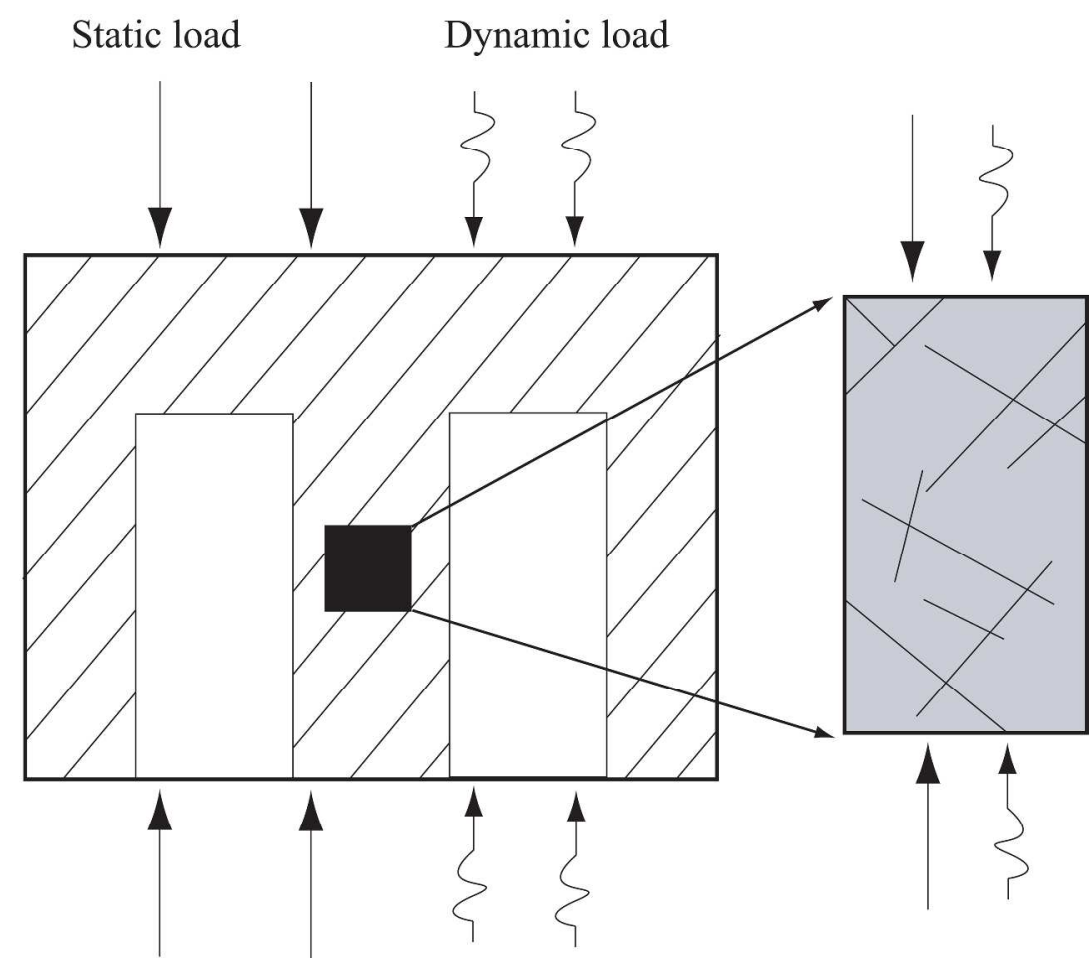

Fig. 1 Schematic diagram of a rock structure at depth subjected to coupled static and dynamic loads $275 \times 199 \mathrm{~mm}(300 \times 300 \mathrm{DPI})$ 
(a)
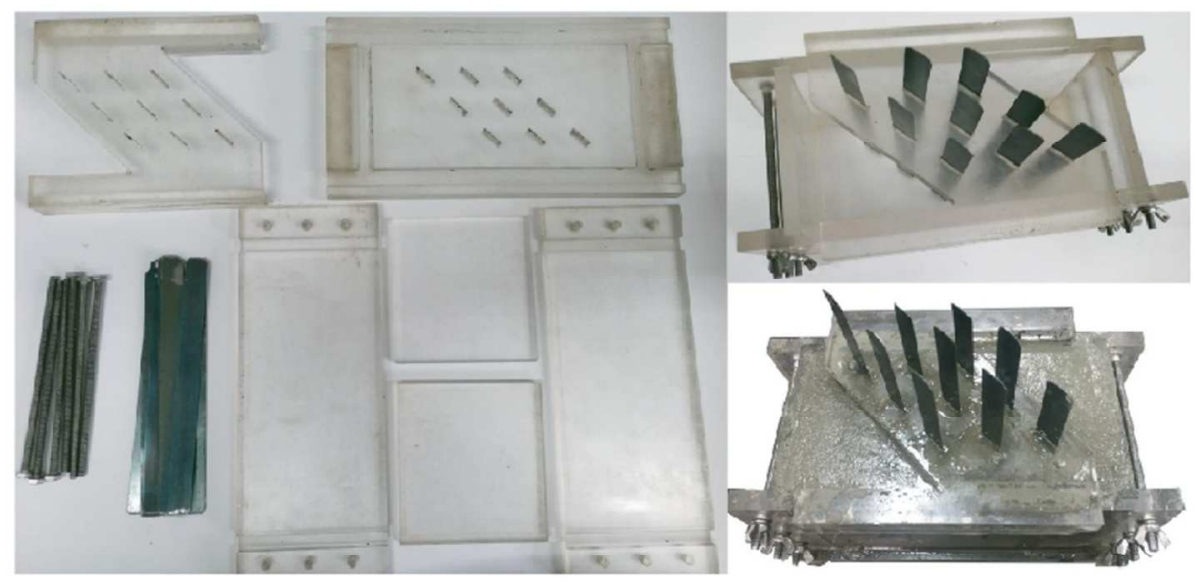

(b)

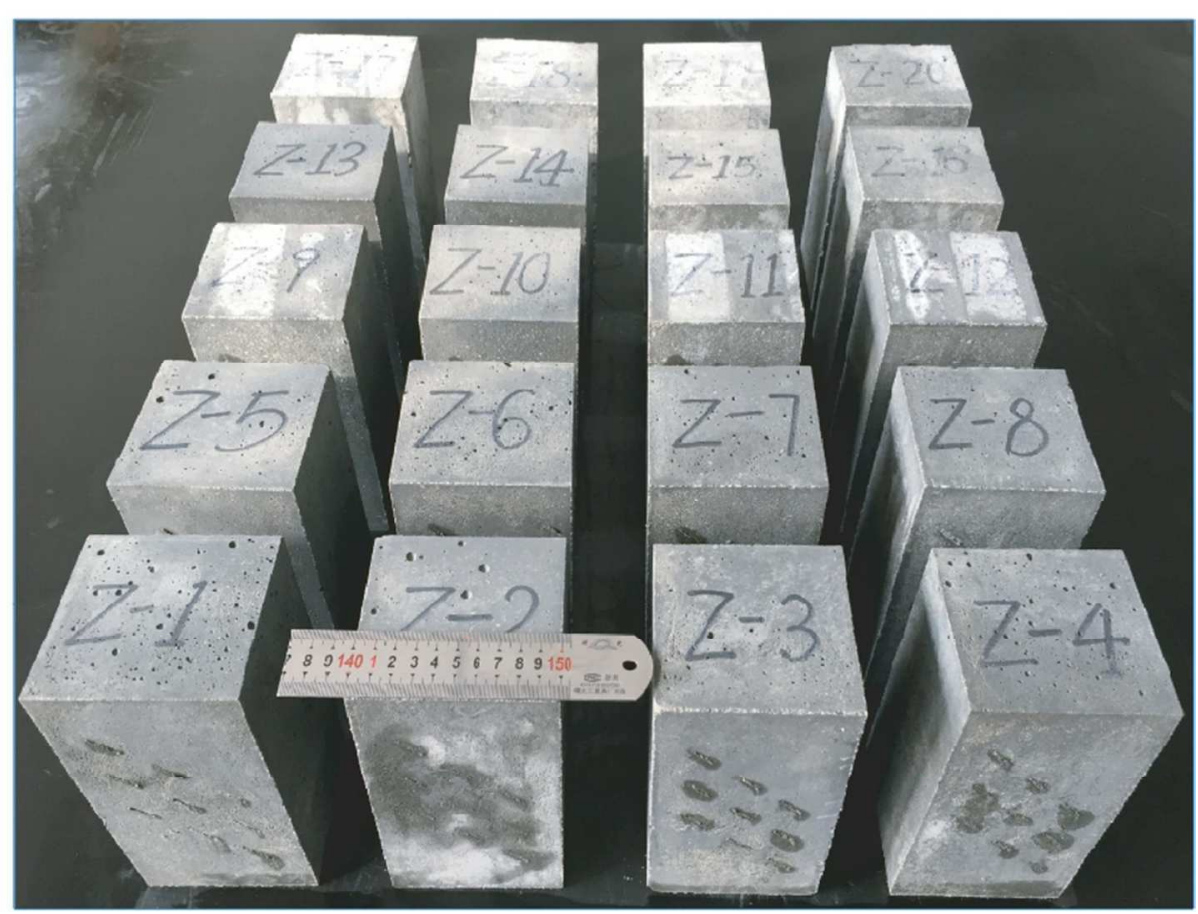

Fig. 2 (a) Customized mold of the rock-like specimen containing intermittent fissures and (b) the fissured specimens prepared for our tests

$92 \times 107 \mathrm{~mm}(300 \times 300 \mathrm{DPI})$ 


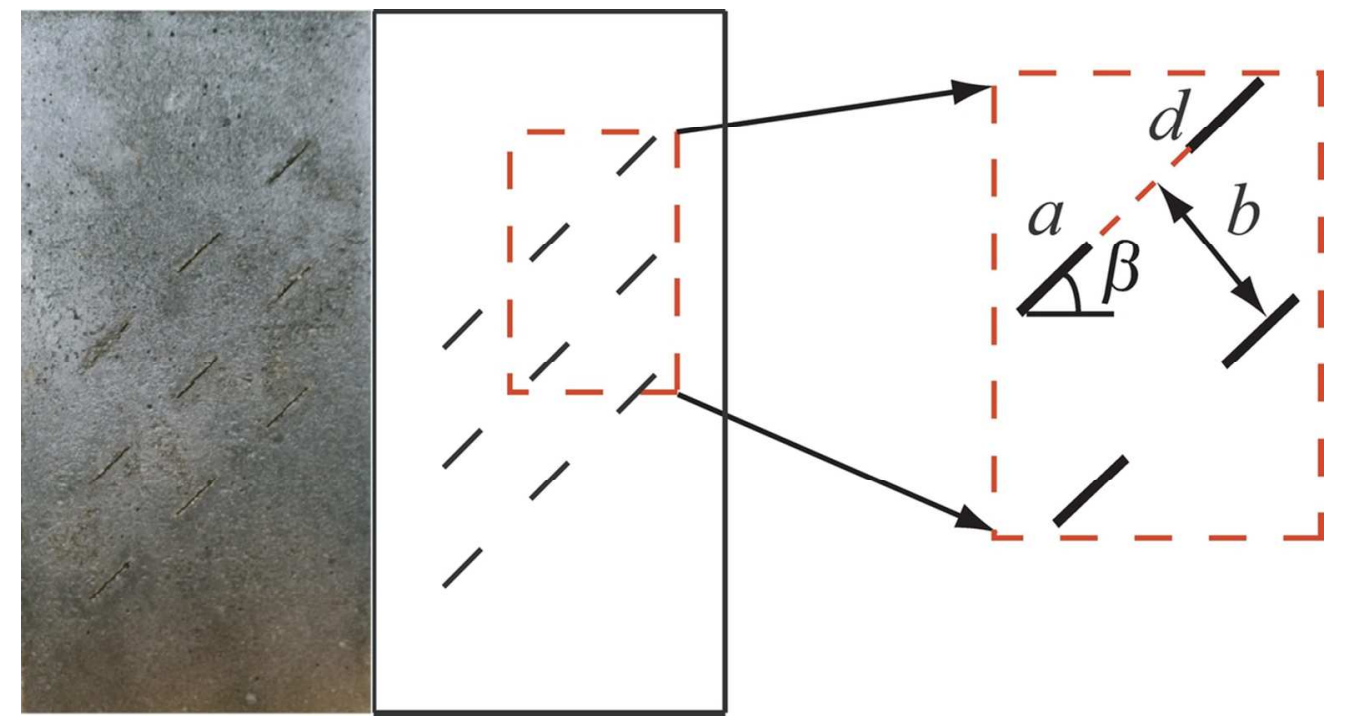

Fig. 3 Schematic of the geometric configurations of the fissured specimen $100 \times 54 \mathrm{~mm}(300 \times 300$ DPI $)$ 

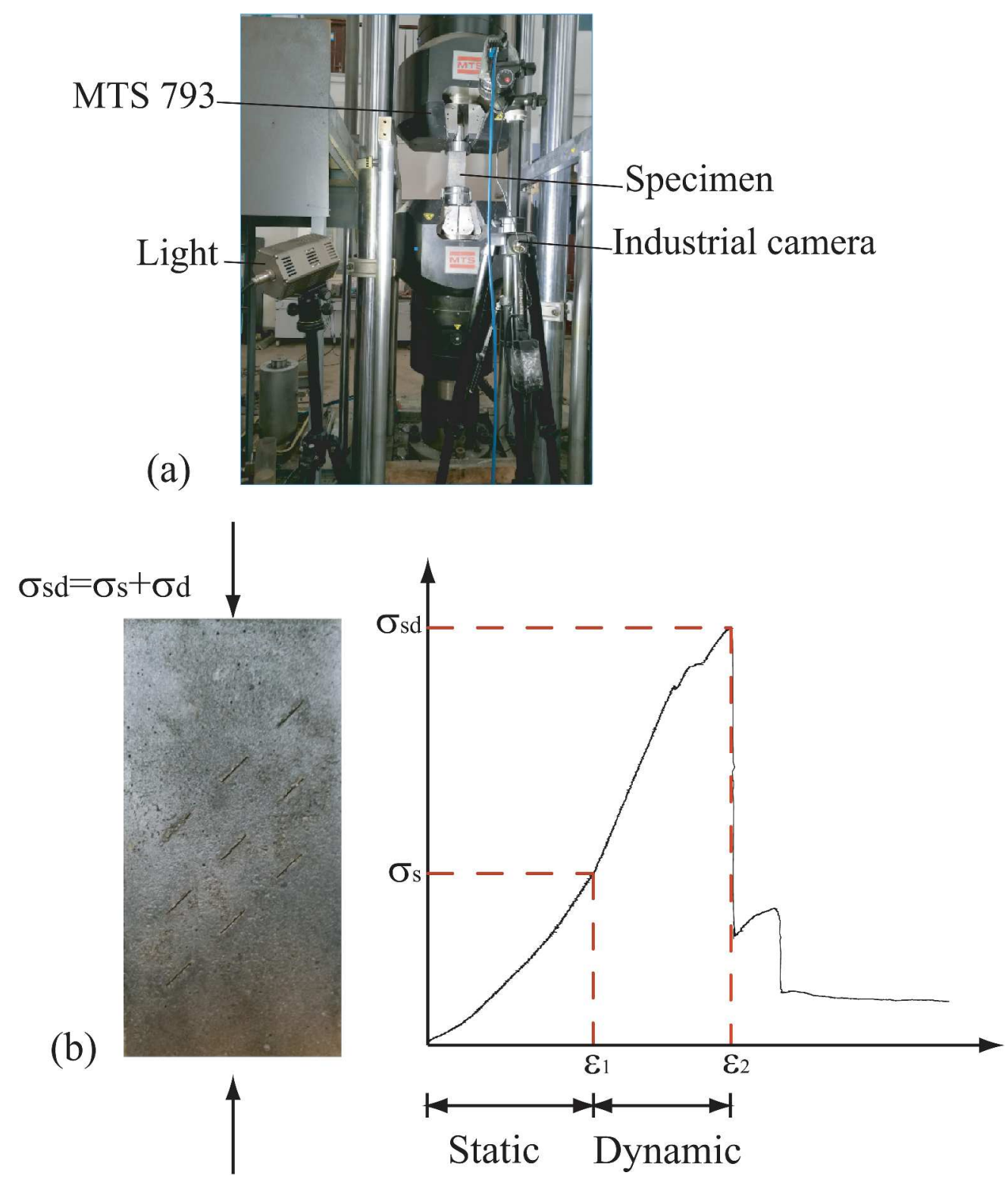

Fig. 4 (a) The MTS-793 rock test system and (b) the tested fissured model and the loading path of coupled static-dynamic loads ( $\sigma s$ represents the static pre-stress, od is the dynamic loading stress, osd is the strength at the coupled loading condition)

$463 \times 545 \mathrm{~mm}(600 \times 600 \mathrm{DPI})$ 


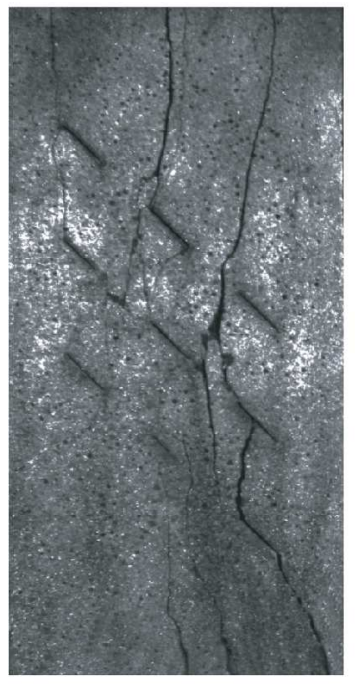

(a)

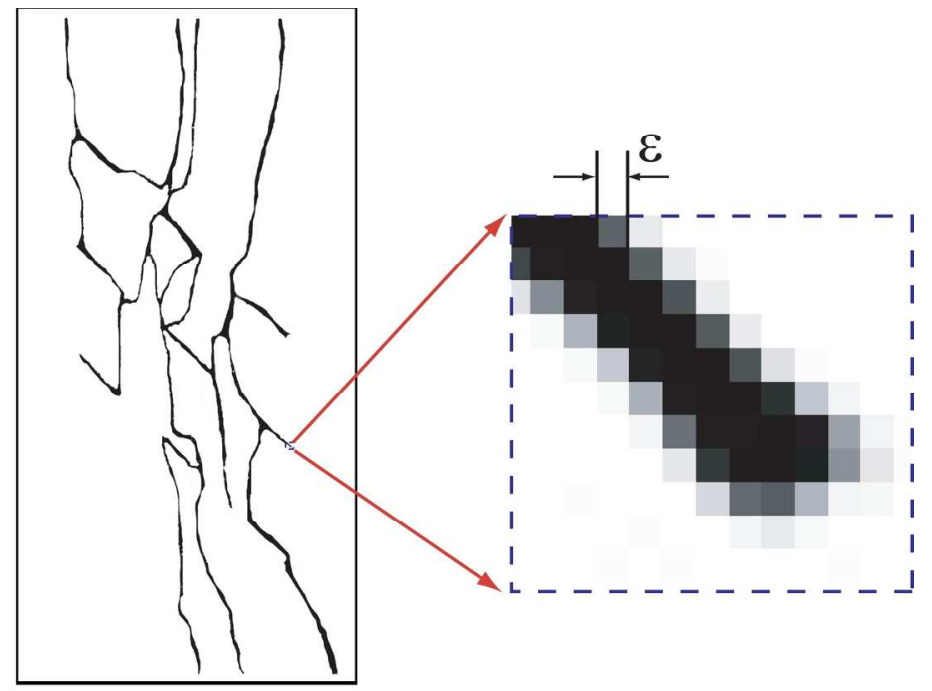

(b) (c)

Fig. 5 The binary reference model (a) the experimental image, (b) the binary image, and (c) the calculated pixels

$182 \times 107 \mathrm{~mm}(300 \times 300$ DPI $)$ 


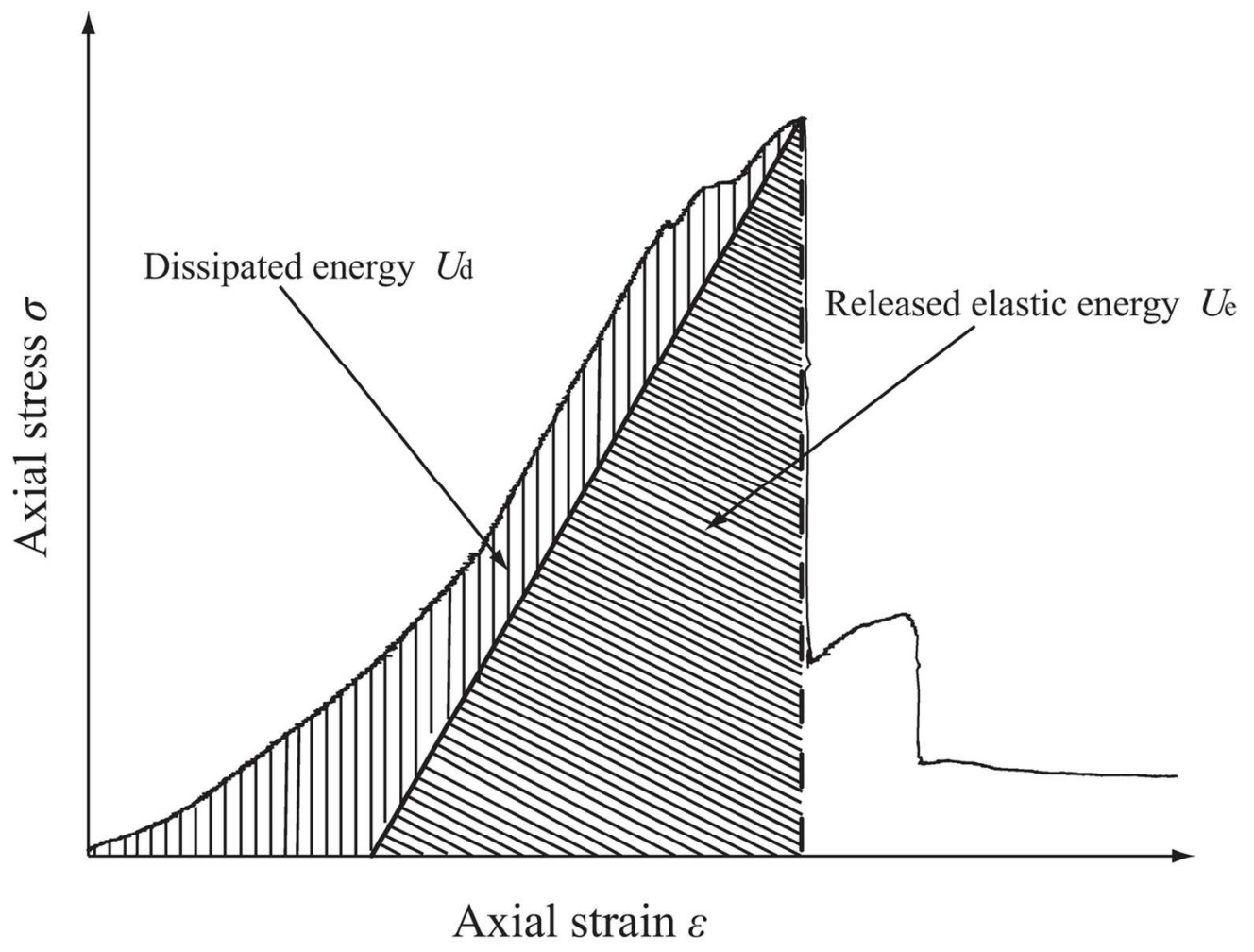

Fig. 6 Quantitative relationship of the energy release and the energy dissipation $124 \times 95 \mathrm{~mm}(300 \times 300 \mathrm{DPI})$ 


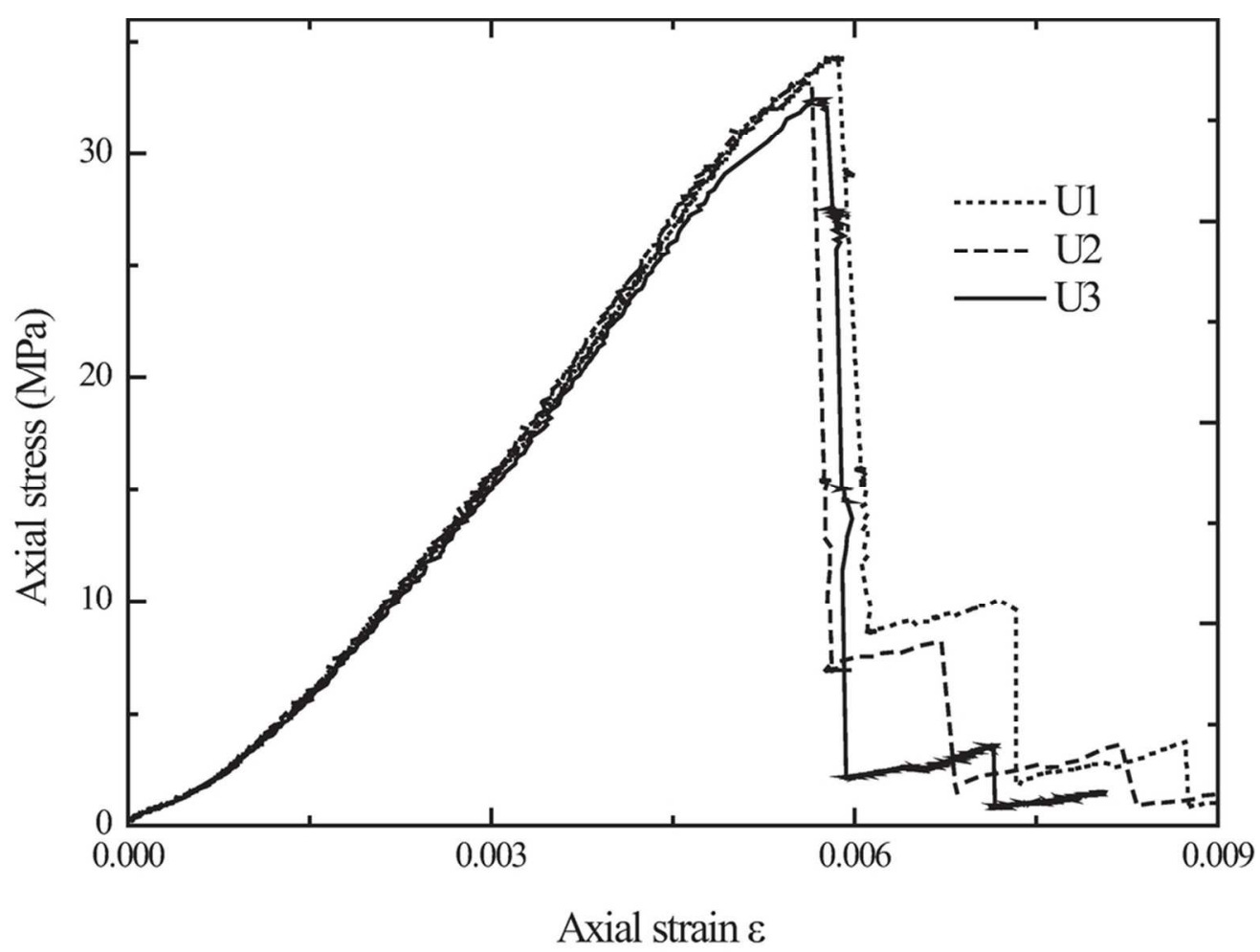

Fig.7 The stress-strain curves of the three tested fissured samples under quasi-static uniaxial compression $88 \times 66 \mathrm{~mm}(300 \times 300 \mathrm{DPI})$ 


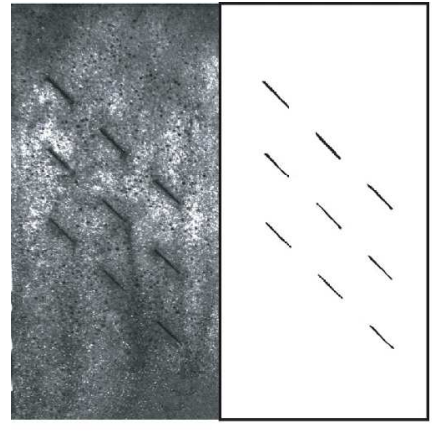

Initial stage

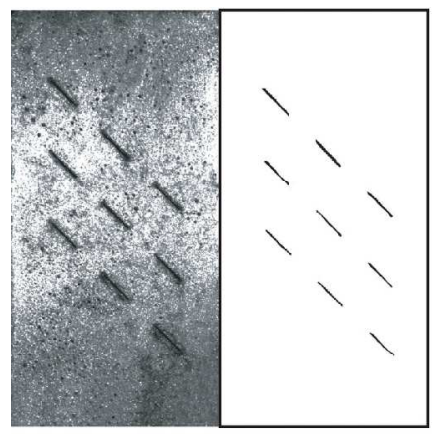

Initial stage

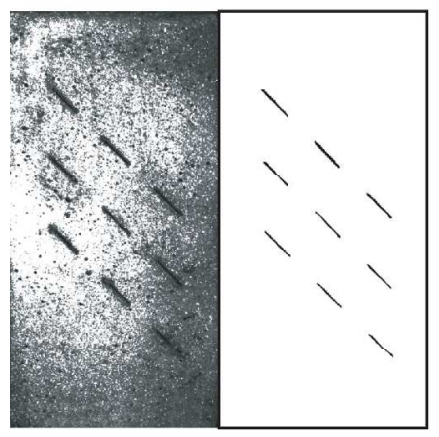

Initial stage

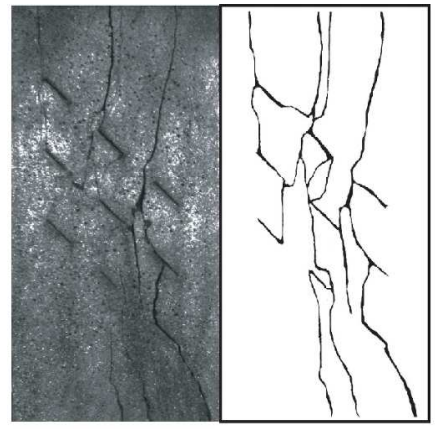

Peak stress

(a) U1

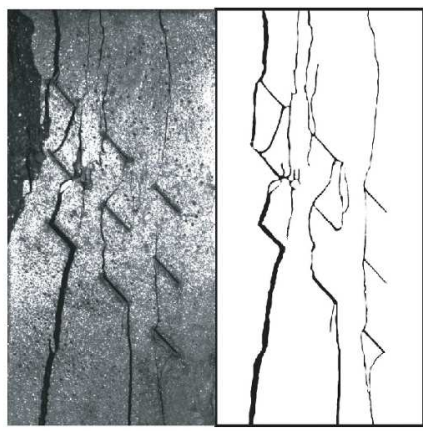

Peak stress

(b) U2

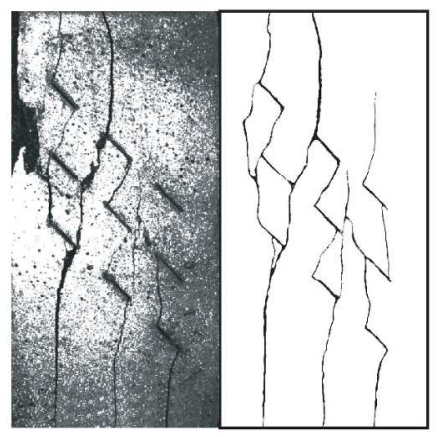

Peak stress

(c) U3

Fig. 8 Failure modes of the three fissured samples under quasi-static uniaxial compression $187 \times 311 \mathrm{~mm}(300 \times 300 \mathrm{DPI})$ 


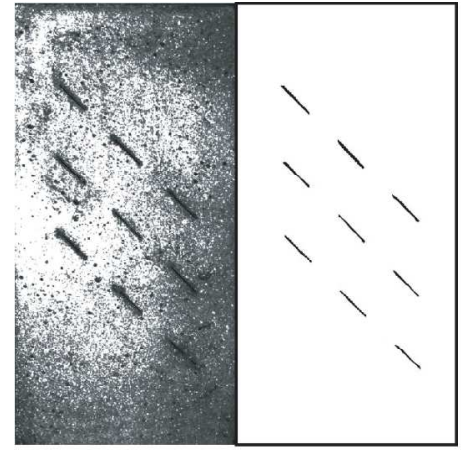

(I) Initial stage

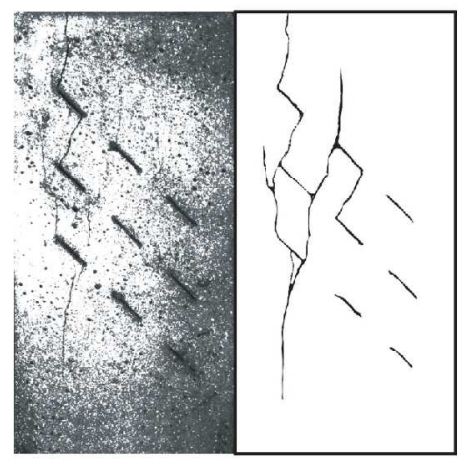

(III) $60 \% \sigma_{\mathrm{c}}$

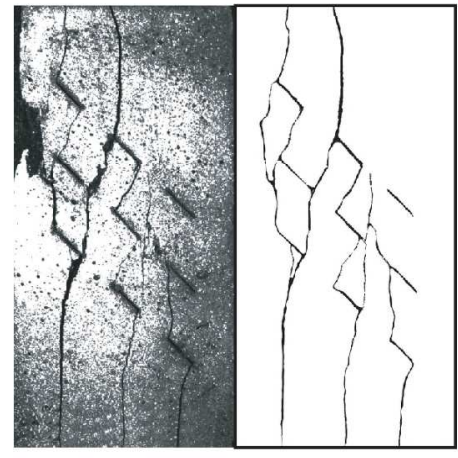

(V) $100 \% \sigma_{\circ}$

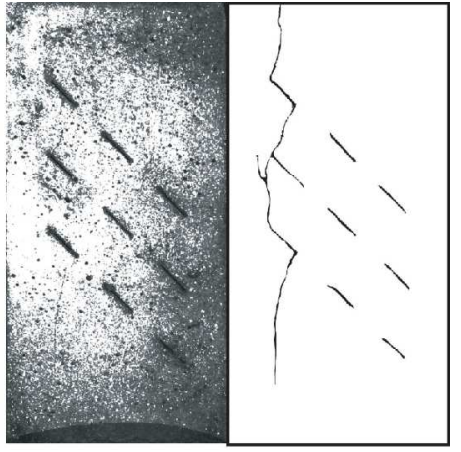

(II) $40 \% \sigma_{\mathrm{c}}$

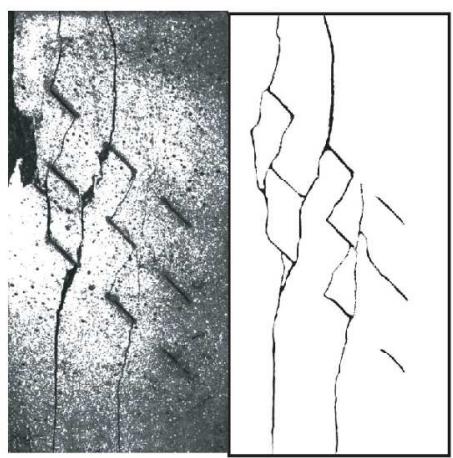

(IV) $80 \% \sigma_{\circ}$

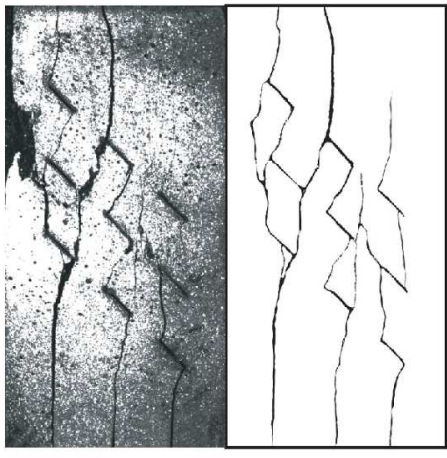

(VI) Post $60 \% \sigma_{c}$

Fig. 9 Progressive failure behavior of the fissured specimen U3 under quasi-static uniaxial compression $177 \times 284 \mathrm{~mm}(300 \times 300$ DPI $)$ 

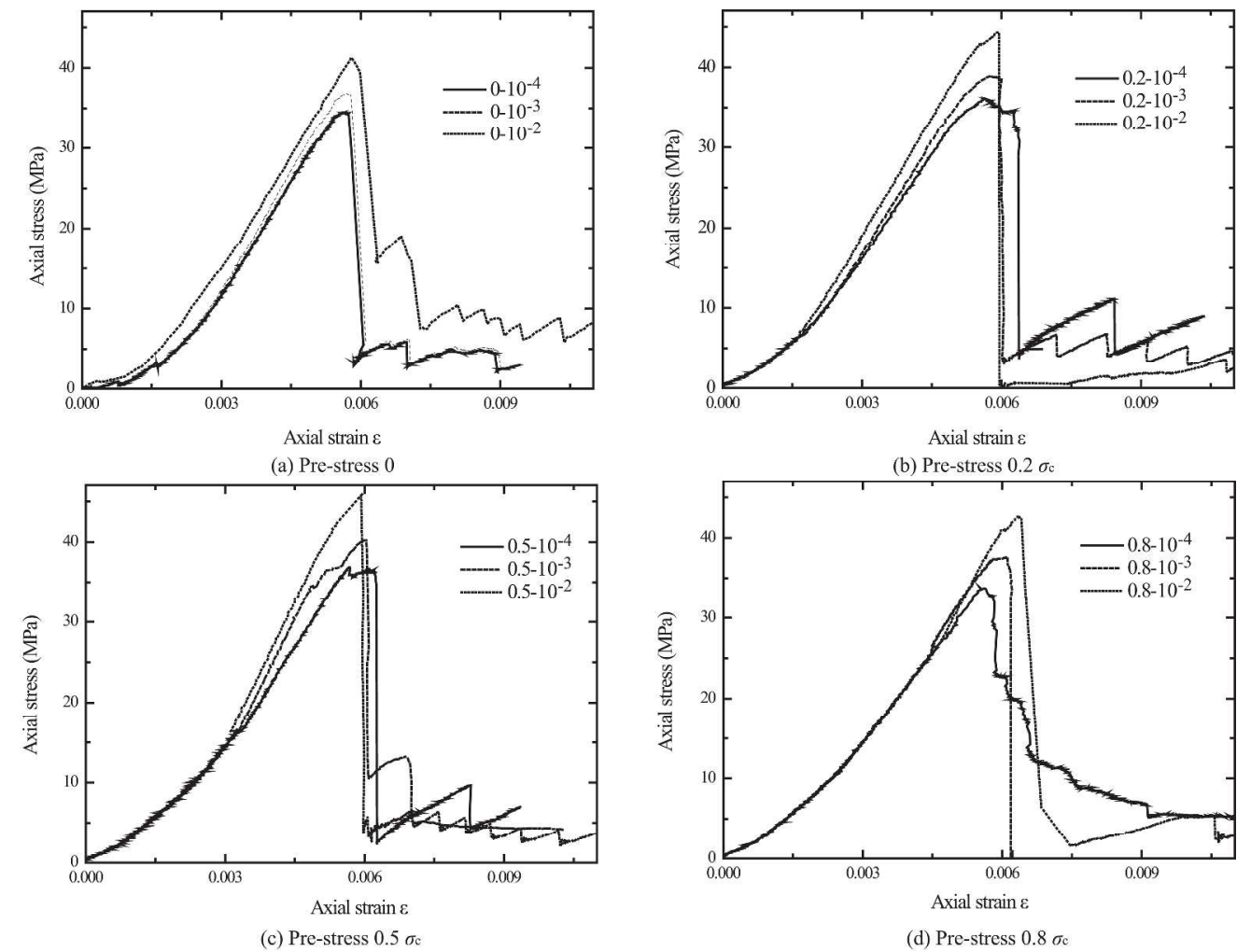

Fig. 10 Stress-strain curves of fissured specimens under coupled loads with static pre-stress of (a) 0 , (b) 0.2 $\sigma c,(c) 0.5 \sigma c$ and (d) $0.8 \sigma c$.

$378 \times 293 \mathrm{~mm}(300 \times 300 \mathrm{DPI})$ 


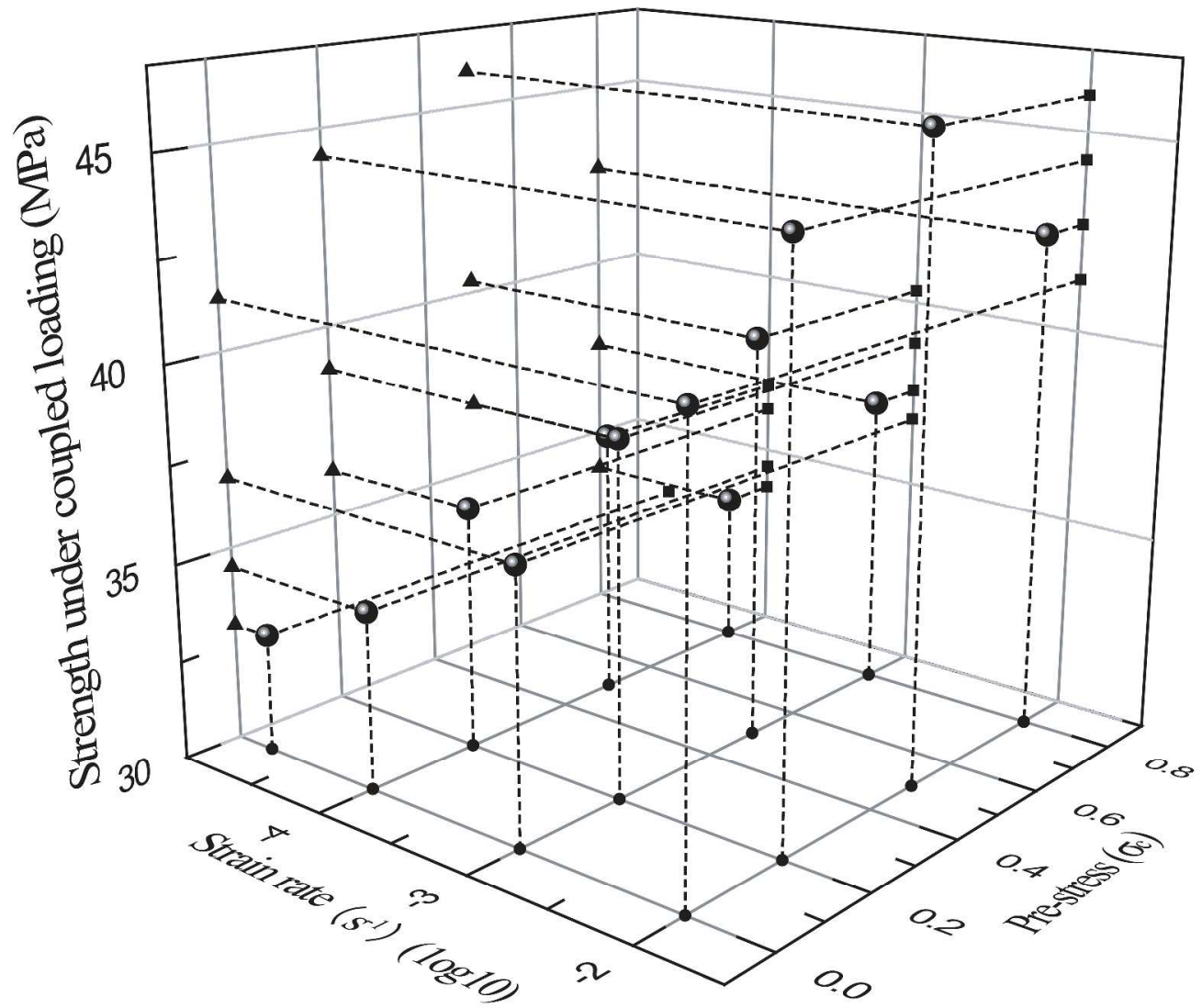

Fig. 11 Strengths of fissured specimens under various coupled static-dynamic loads $539 \times 452 \mathrm{~mm}(600 \times 600 \mathrm{DPI})$ 


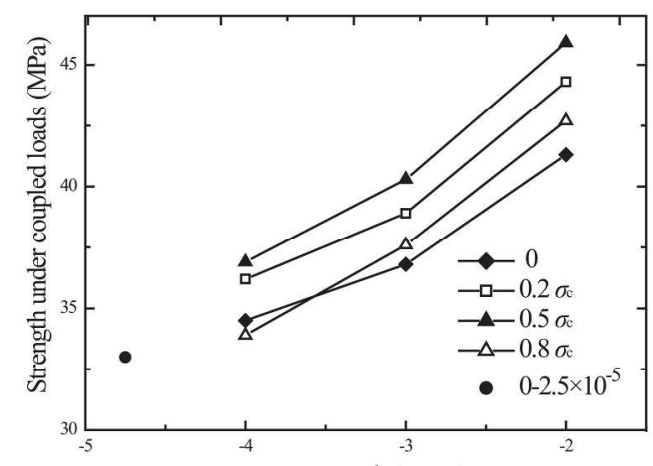

(a) Strain rate $\left(\mathrm{s}^{-1}\right)(\log 10)$

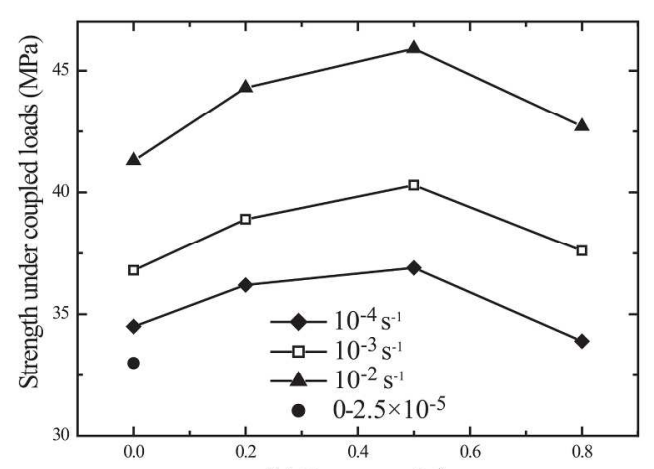

(b) Pre-stress $\left(\sigma_{c}\right)$

Fig. 12 Influences of (a) the static pre-stress and (b) the dynamic strain rate on the strength of fissured specimens under coupled loads

$228 \times 90 \mathrm{~mm}(300 \times 300$ DPI $)$ 

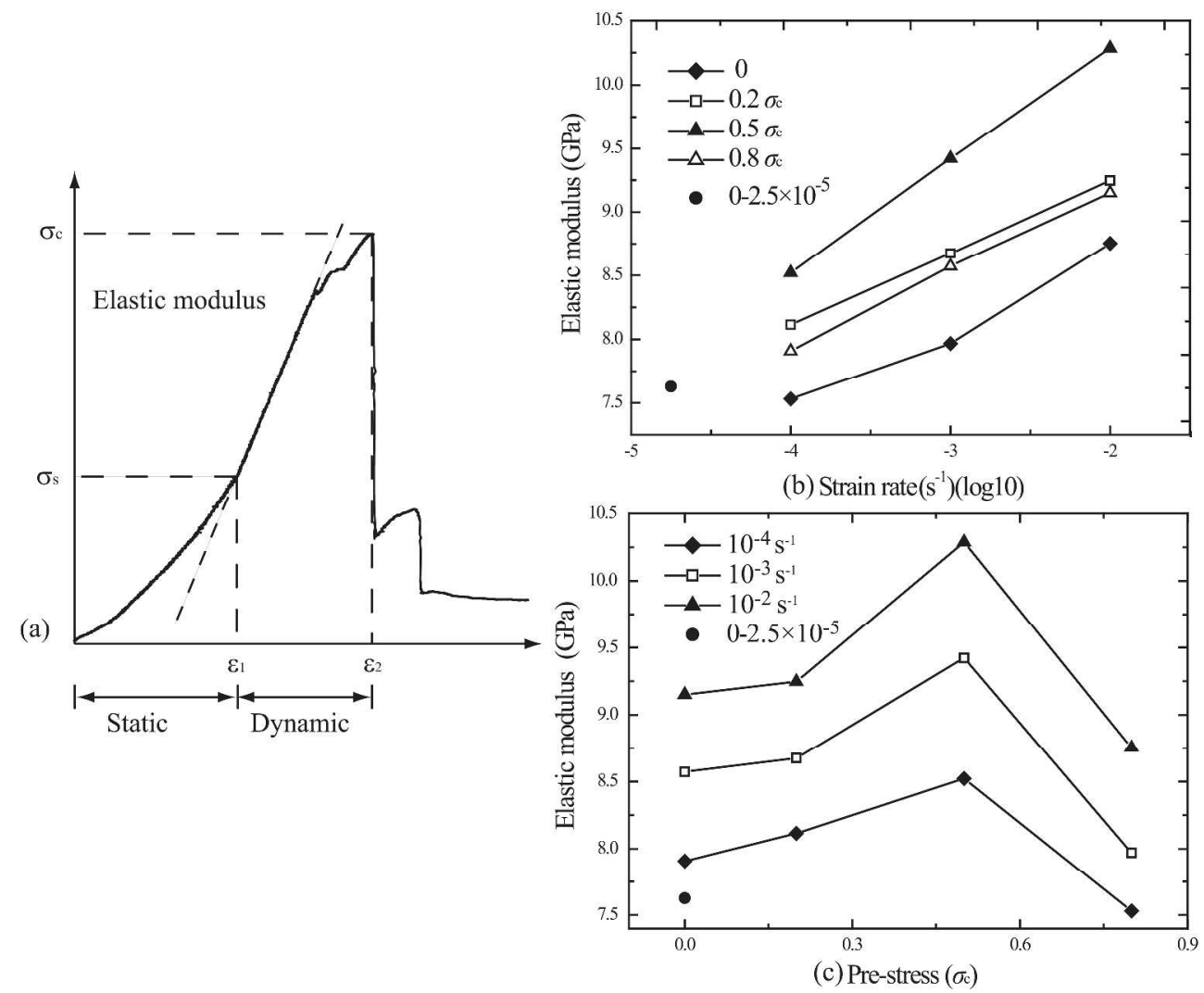

Fig. 13 (a) The determination of the elastic modulus of a fissured specimen under coupled static-dynamic loads, and influences of (b) the dynamic strain rate and (c) the static pre-stress on the elastic modulus of fissured specimens under coupled loads

$$
575 \times 467 \mathrm{~mm}(600 \times 600 \mathrm{DPI})
$$




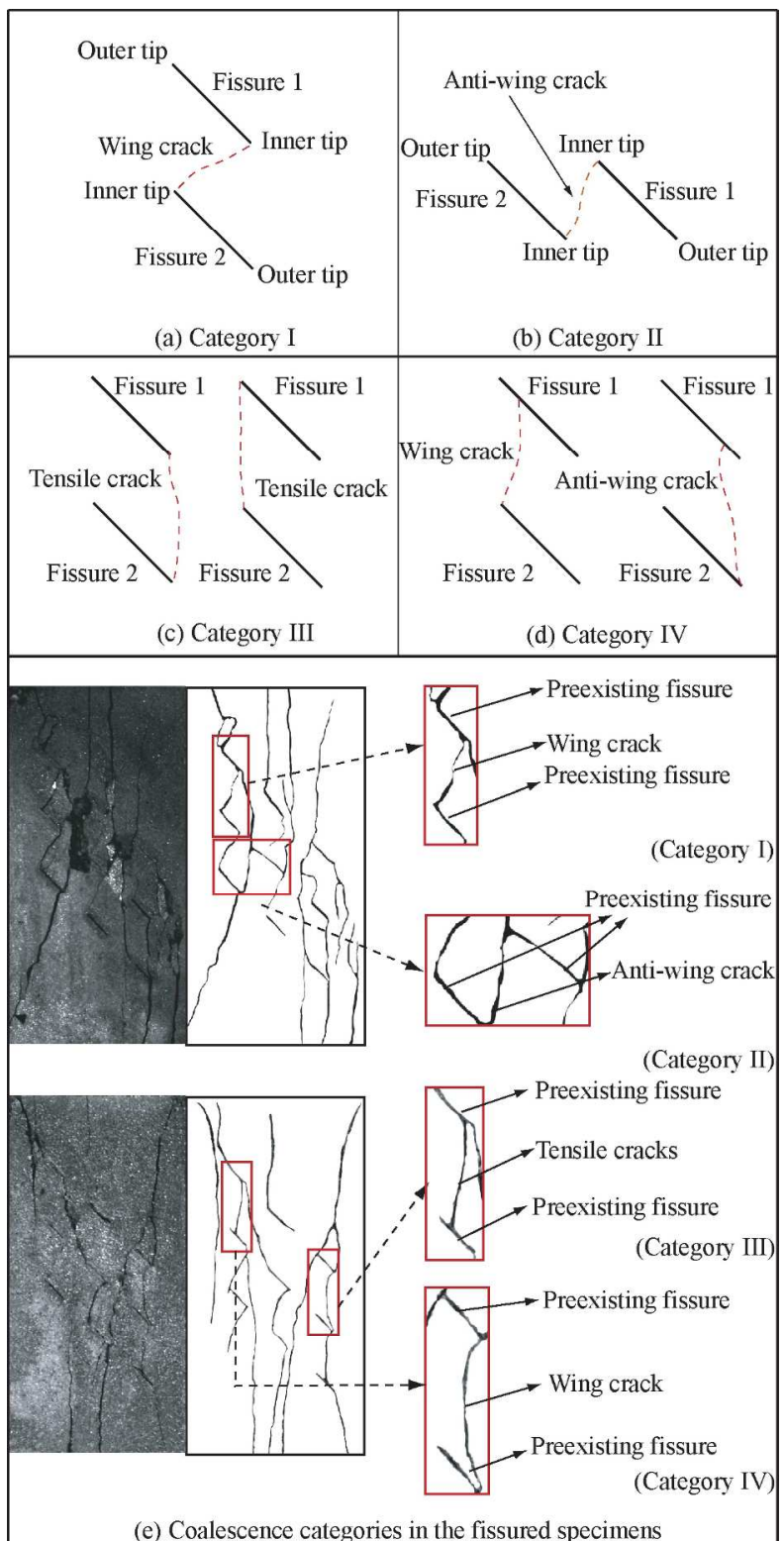

Fig. 14 Coalescence categories of fissured specimens under different coupled static-dynamic loads $216 \times 433 \mathrm{~mm}(300 \times 300$ DPI $)$ 


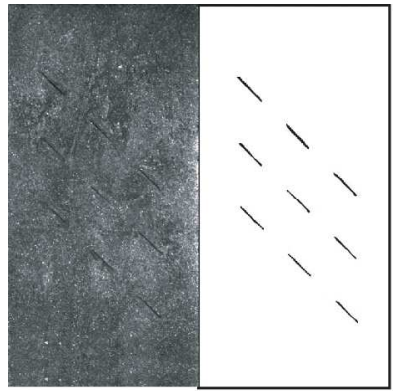

Static pre-stress of zero

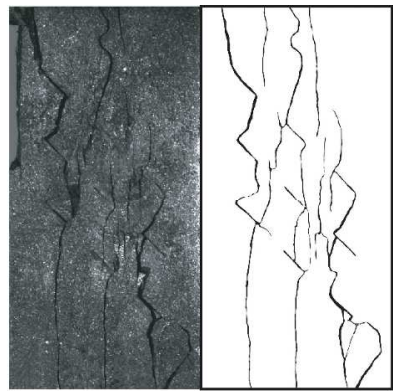

Peak stress

(a) Dynamic strain rate of $10^{-4} \mathrm{~s}^{-1}$

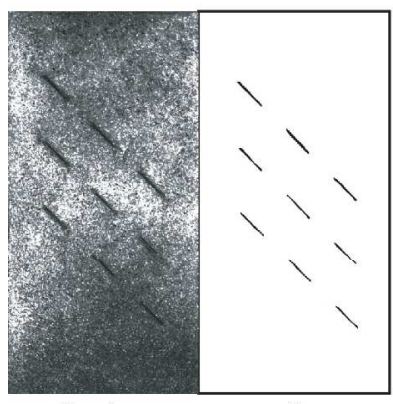

Static pre-stress of zero

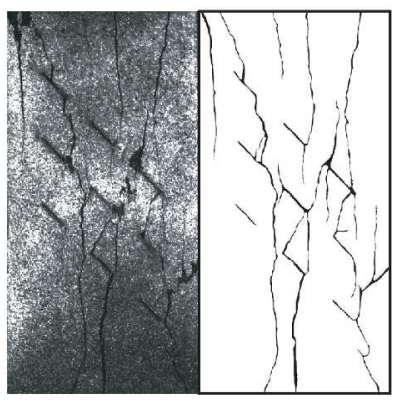

Peak stress

(b) Dynamic strain rate of $10^{-3} \mathrm{~s}^{-1}$

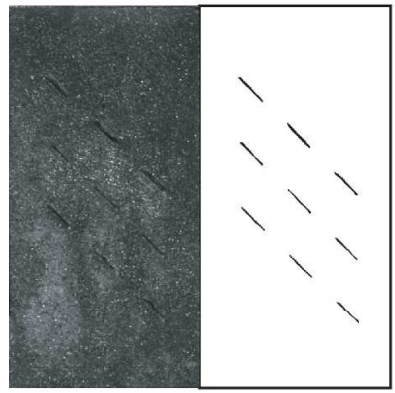

Static pre-stress of zero

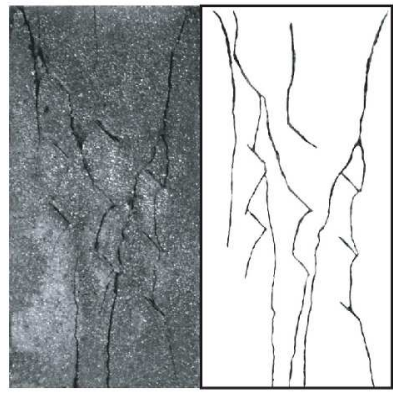

Peak stress

(c) Dynamic strain rate of $10^{-2} \mathrm{~s}^{-1}$

Fig. 15 The failure modes of the fissured specimen with zero pre-stress under dynamic strain rates of (a) 10-4 s-1, (b) 10-3 s-1, and (c) 10-2 s-1

$204 \times 369 \mathrm{~mm}(300 \times 300$ DPI $)$ 


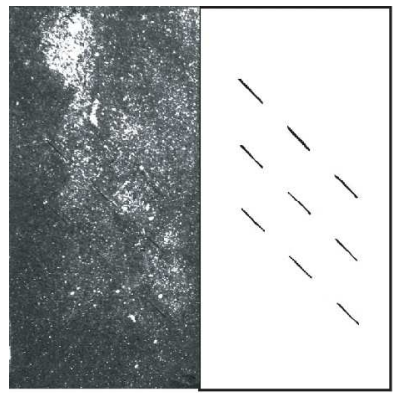

Static pre-stress of $20 \% \sigma_{\mathrm{c}}$

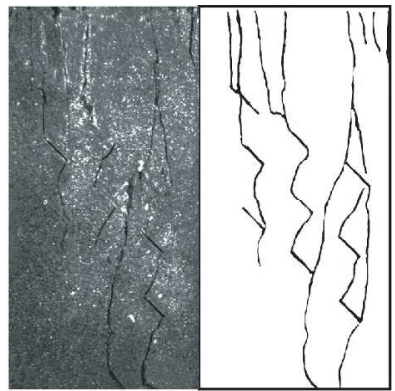

Peak stress

(a) Dynamic strain rate of $10^{-4} \mathrm{~s}^{-1}$

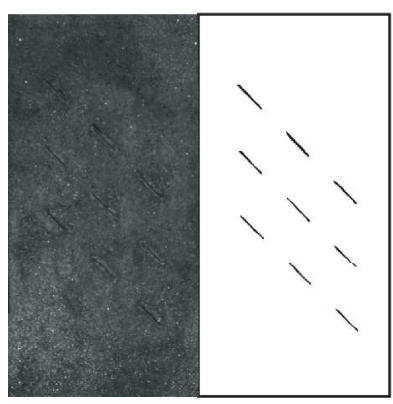

Static pre-stress of $20 \% \sigma_{\mathrm{c}}$

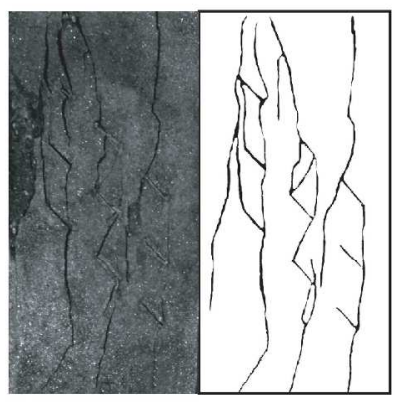

Peak stress

(b) Dynamic strain rate of $10^{-3} \mathrm{~s}^{-1}$

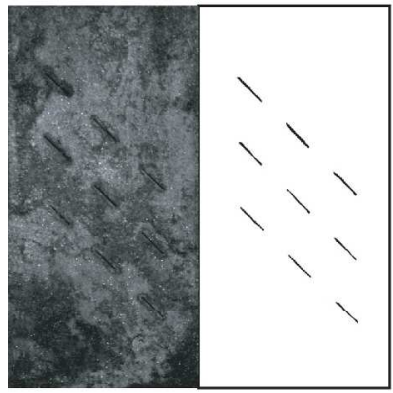

Static pre-stress of $20 \% \sigma_{\mathrm{c}}$

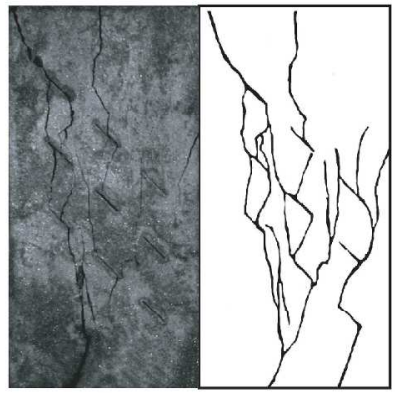

Peak stress

(c) Dynamic strain rate of $10^{-2} \mathrm{~s}^{-1}$

Fig. 16 The failure modes of the fissured specimen with a pre-stress of $0.2 \sigma c$ under dynamic strain rates of (a) 10-4 s-1, (b) 10-3 s-1, and (c) 10-2 s-1

$204 \times 369 m m(300 \times 300$ DPI $)$ 


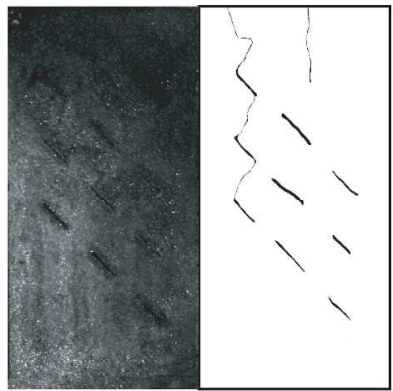

Static pre-stress of $50 \% \sigma_{\mathrm{c}}$

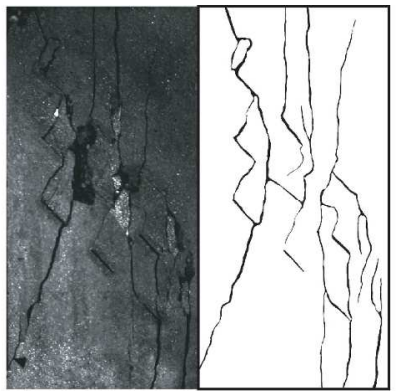

Peak stress

(a) Dynamic strain rate of $10^{-4} \mathrm{~s}^{-1}$

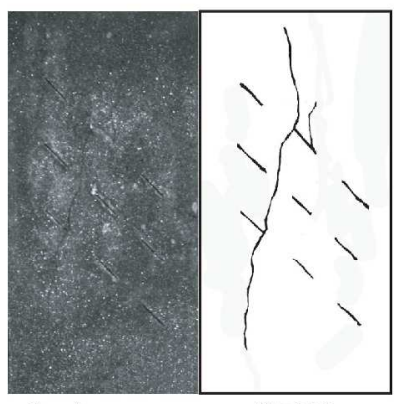

Static pre-stress of $50 \% \sigma_{\mathrm{c}}$

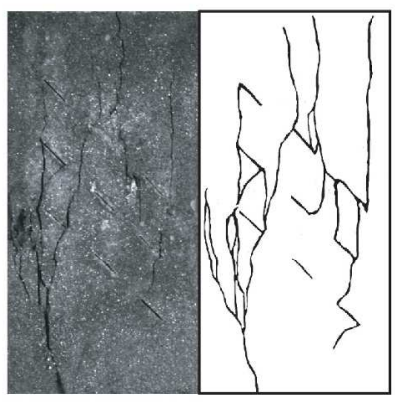

Peak stress

(b) Dynamic strain rate of $10^{-3} \mathrm{~s}^{-1}$

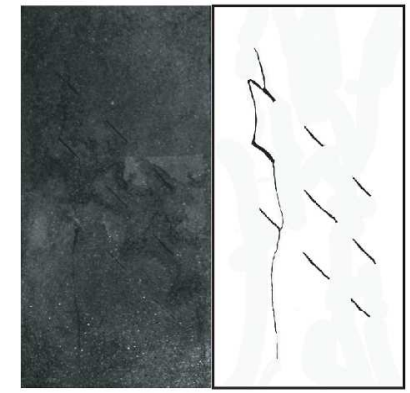

Static pre-stress of $50 \% \sigma_{\mathrm{c}}$

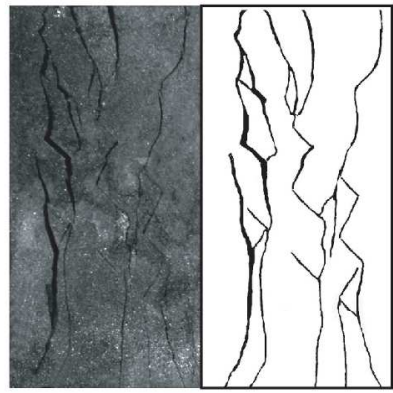

Peak stress

(c) Dynamic strain rate of $10^{-2} \mathrm{~s}^{-1}$

Fig. 17 The failure modes of the fissured specimen with a pre-stress of $0.5 \sigma \mathrm{c}$ under dynamic strain rates of (a) 10-4 s-1, (b) 10-3 s-1, and (c) 10-2 s-1

$204 \times 368 \mathrm{~mm}(300 \times 300$ DPI $)$ 


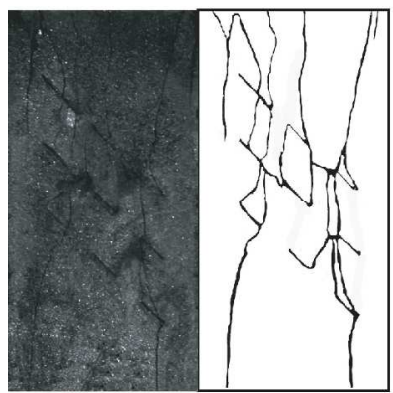

Static pre-stress of $80 \% \sigma_{c}$

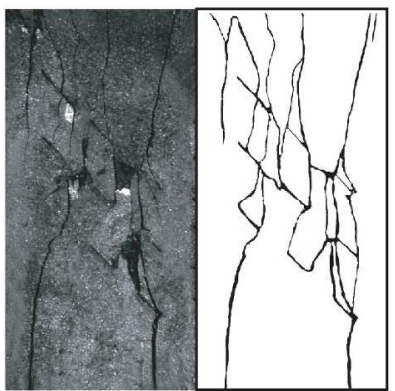

Peak stress

(a) Dynamic strain rate of $10^{-4} \mathrm{~s}^{-1}$

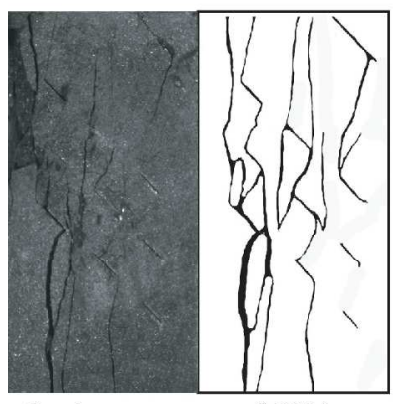

Static pre-stress of $80 \% \sigma_{\mathrm{c}}$

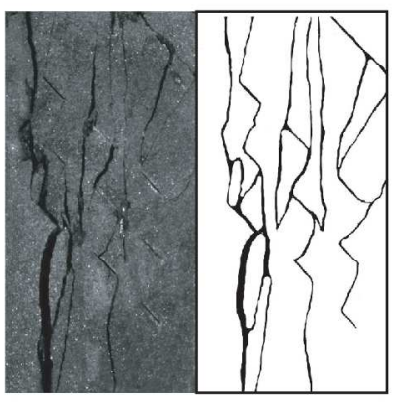

Peak stress

(b) Dynamic strain rate of $10^{-3} \mathrm{~s}^{-1}$

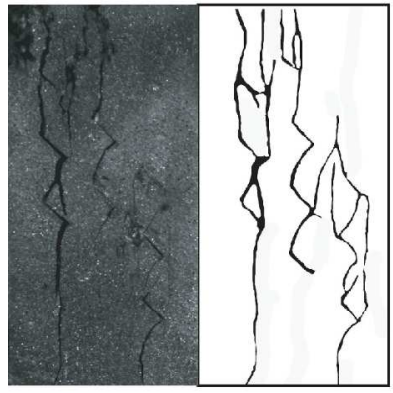

Static pre-stress of $80 \% \sigma_{\mathrm{c}}$

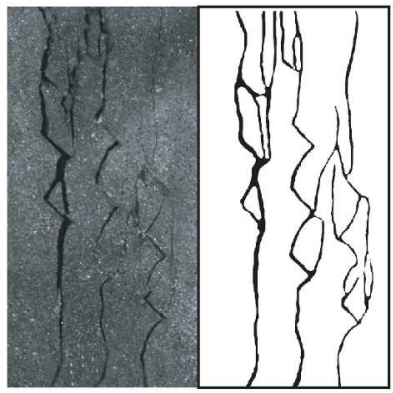

Peak stress

(c) Dynamic strain rate of $10^{-2} \mathrm{~s}^{-1}$

Fig. 18 The failure modes of the fissured specimen with a pre-stress of $0.8 \sigma \mathrm{c}$ under dynamic strain rates of (a) 10-4 s-1, (b) 10-3 s-1, and (c) 10-2 s-1

$204 \times 370 \mathrm{~mm}(300 \times 300 \mathrm{DPI})$ 


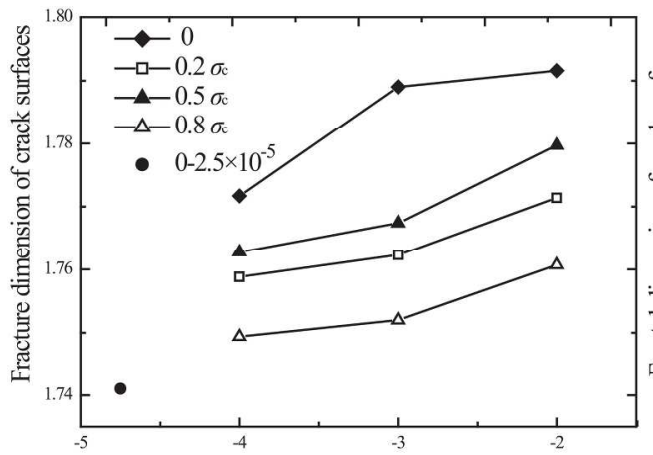

(a) Strain rate $\left(\mathrm{s}^{-1}\right)(\log 10)$

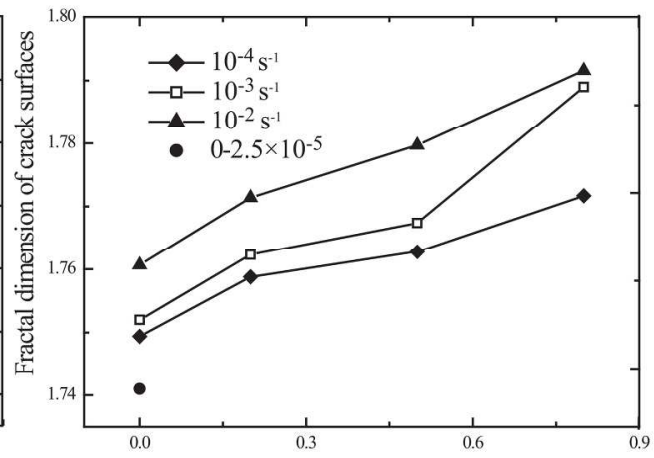

(b) Pre-stress $\left(\sigma_{c}\right)$

Fig. 19 Influences of (a) the dynamic strain rate and (b) the static pre-stress on the fractal dimension of crack surfaces of fissured specimens under coupled loads

$$
223 \times 83 \mathrm{~mm}(300 \times 300 \mathrm{DPI})
$$




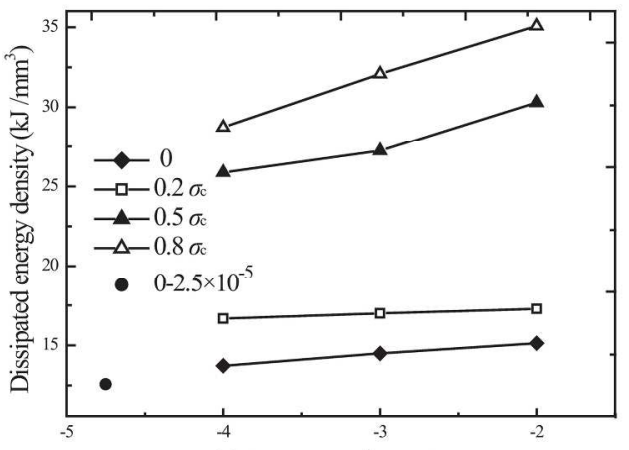

(a) Strain rate $\left(\mathrm{s}^{-1}\right)(\log 10)$

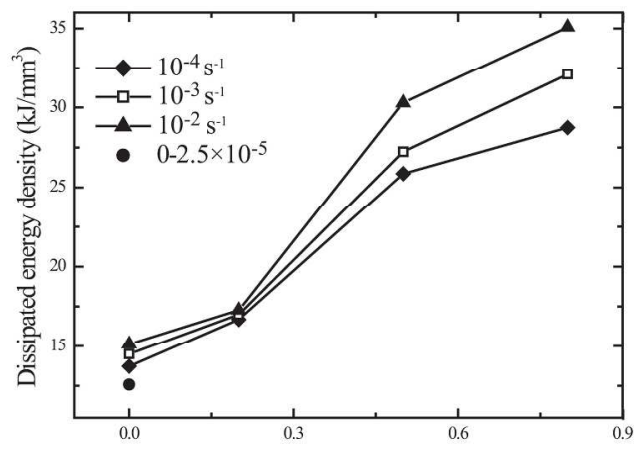

(c) Pre-stress $\left(\sigma_{c}\right)$

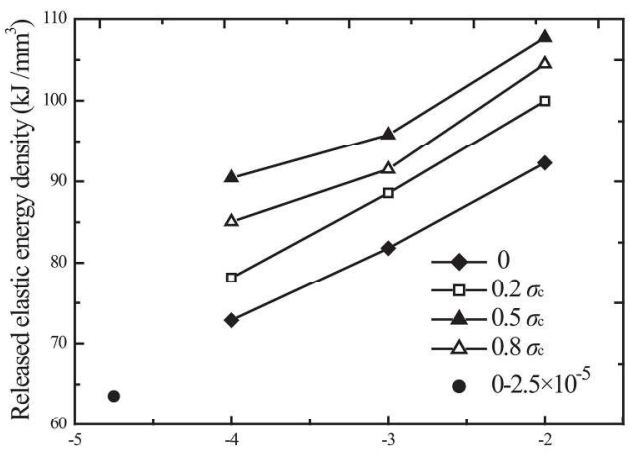

(b) Strain rate $\left(\mathrm{s}^{-1}\right)(\log 10)$

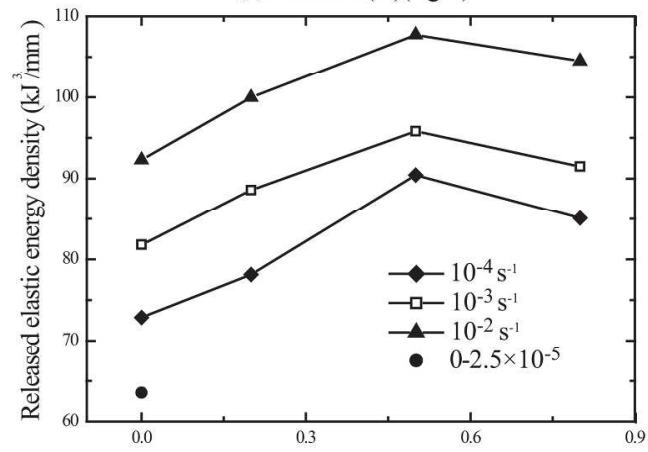

(d) Pre-stress $\left(\sigma_{c}\right)$

Fig. 20 Influences of the dynamic strain rate on (a) the dissipated energy density and (b) the released elastic energy density, and influences of the static pre-stress on (c) the dissipated energy density and (d) the released elastic energy density

\section{$220 \times 162 \mathrm{~mm}(300 \times 300 \mathrm{DPI})$}

